\title{
Behavioral Responses of a Generalist Pest, Spilosoma Obliqua Walker, Towards the Leaf Surface Wax Chemicals of Three Types of Jute Crop and Implications in Pest Management
}

Nayan Roy ( nayan909@gmail.com )

M.U.C. Women's College, Burdwan https://orcid.org/0000-0002-0114-0596

Syed Husne Mobarak

University of Burdwan

\section{Research Article}

Keywords: Jute, Spilosoma obliqua, n-alkanes, free fatty acids, baited trap, IPM

Posted Date: December 20th, 2021

DOI: https://doi.org/10.21203/rs.3.rs-1148811/v1

License: (c) (i) This work is licensed under a Creative Commons Attribution 4.0 International License. Read Full License 


\section{Abstract}

Behavioral responses of a generalist pest, Spilosoma obliqua Walker (Lepidoptera: Arctiidae), towards the leaf surface wax chemicals of three types of jute crops (white jute, Corchorus capsularis, tossa jute, $C$. olitorious, and mesta jute or kenaf, Hibiscus cannabinus [Malvaceae]) and their implications in pest management was studied under laboratory conditions. The GCMS and GC-FID analyses of the jute leaf epicuticular waxes indicated the presence of $27 n$-alkanes, having chain lengths from n$\mathrm{C}_{14}$ to $\mathrm{n}-\mathrm{C}_{36}$ and 14 free fatty acids (FFAs) having chain lengths from $\mathrm{C}_{12: 0}$ to $\mathrm{C}_{22: 0}$. Among the identified $\mathrm{n}$-alkanes and FFAs of selected jute cultivars $\mathrm{n}-\mathrm{C}_{34}\left(144.397 \pm 6.971 \mu \mathrm{g} \mathrm{leaf}^{-1}\right)$ and $\mathrm{C}_{16: 1}\left(37.034 \pm 0.848 \mathrm{~g} \mathrm{leaf}^{-1}\right)$ of tossa jute leaves were most abundant. The host preference (white jute> tossa jute > mesta jute) of $S$. obliqua was evaluated simultaneously by olfactory, visual, and tactile recognition, as valid for other lepidopteran species. For olfaction [females], oviposition [gravid females], and feeding [larvae]) in S. obliqua, the most stimulating combined-synthetic-mixture of epicuticular wax components was represented by 4 -alkanes $\left(n-C_{16}, n-C_{18}, n-C_{20}, n-C_{22}\right)$ and 5 FFAs $\left(C_{16: 1}, C_{16: 0}, C_{18: 0}, C_{20: 0}, C_{22: 0}\right)$ in mixture at leaf equivalent $\left(\mu\right.$ leaf $\left.^{-1}\right)$ amounts $(195.209 \pm 2.950 \mu \mathrm{g}, 119.777 \pm 1.857 \mu \mathrm{g}$, and $50.567 \pm 3.508 \mu \mathrm{g}$, respectively) in white jute, tossa jute, and mesta jute, respectively. Thus, the present study suggests that the synthetic blends of $4 \mathrm{n}$-alkanes and 5 FFAs of respective jute crops can be used as lures to develop baited trap as a part of integrated pest management (IPM) of $S$. obliqua for sustainable jute cultivation.

\section{Introduction}

Three types of jute crops (Corchorus capsularis [white jute], C. olitorious [tossa jute], and Hibiscus cannabinus [mesta jute or kenaf ] [Malvaceae]) are the most important economic fiber crop throughout the world after cotton (Kumar et al. 2014, 2017; Mahapatra et al. 2009; Sarkar and Majumdar 2016). Presently, jute cultivation is gaining importance in India particularly in rain fed tracts of eastern transitional zones due to its increasing demand as eco-friendly green raw material for different industries (Naik and Karmakar 2016; Mazumdar et al. 2016; Roy 2015b). However, several limiting (biotic and abiotic) factors regulate agricultural production of jute throughout the world (Sarkar and Gawande 2016; Sarkar and Majumdar 2013; Rahaman and Khan 2006, 2012). Among the pests, the Bihar hairy caterpillar (BHC), Spilosoma obliqua Walker, syn. Diacrisia obliqua, (Lepidoptera, Arctiidae), is considered to be a potent pest in India including West Bengal (Gotyal et al. 2015; Mobarak et al. 2020b; Singh and Varatharajan 1999; Roy 2020). This generalist is one of the major pests on different economic crops in South East Asian countries including India (Bhaduria et al. 2001; Roy and Barik 2013; Roy 2020; Varatharajan et al. 1998). Being a sporadically occurring and polyphagous pest, its larval survival and development vary greatly on a wide range of its host plants such as oilseed crops, fibre crops, pulses, legumes, vegetables, medicinal plants, weeds, etc. (Singh and Singh 1992; Roy 2020). Their larval instars (I-VI) feed voraciously on their host leaves and the plants may be completely defoliated (Mobarak et al. 2020b; Roy 2020). The $3_{\mathrm{rd}}$-to- $5_{\text {th }}$ instar larvae are the most damaging ones and cause a severe reduction of host yield (Mobarak et al. 2020b; Singh and Singh 1992; Roy 2020). The larvae showed a certain level of resistance to different classes of insecticides including a few biorationals and, hence, the successful control of this pest is to some extent difficult (Mohapatra and Gupta 2018; Parui and Roy 2016). Unfortunately, due to different socioeconomic attributes, still farmers are generally use broad-spectrum synthetic pesticides injudiciously (Carvalho 2017; Kumar et al. 2017). These result into secondary pest outbreak, pest resurgence, development of pesticide resistance and emergence of pest biotypes and creates ecological imbalance (Aktar et al. 2009; Kim et al., 2017; Mathew 2016). To face this ecosystem crisis, development of more sustainable methods of crop production as a part of integrated pest management (IPM) is a worldwide concern today (Kumar et al. 2014; Roy, 2020, 2021a, b).

Precise knowledge about chemical mediated plant-insect interactions between the fibre crops and the pest, $S$. obliqua, is required for their successful IPM. For many years, numerous studies have been conducted to control insect pests through plant-based semiochemicals (Mobarak et al. 2020a; Roy 2019a 2021b). Isolation and identification of semiochemical compounds responsible for triggering insect behaviour can enhance a better understanding of insect-plant interactions (Little et al. 2019; Renwick and Chew 1994; Schoonhoven et al. 2005). Herbivorous insects recognize their host plants by several physicochemical cues detected through different sensory modalities (Chapman and Bernays 1989; Lucas-Barbosa et al. 2016; Raguso and Willis 2005; Roy 2019a). They find host plants through visual (Barragan-Fonseca et al. 2020; Dahanukar et al. 2005; Goyret et al. 2007; Wadhera and Capaldi-Philips 2014), olfactory (Roy and Barik 2012b, 2014; Das et al. 2019; Mitra et al. 2017; Roy et al. 2012a), tactile (Foster and Howard 1998; Roy 2019a), and gustatory (Chapman 2003; Feng et al. 2017; Van Loon et al. 1992) cues

Page $2 / 21$ 
individually or in combinations with each other (Aartsma et al. 2017; Omura et al. 1999; Roy 2019a, 2021b). Thus, the plant signals play a crucial role in the survival of most phytophagous insects, particularly in lepidopterans, because their neonates are often relatively immobile and, thus, depend on the judicious choice of the host plant by the adult females (McCallum et al. 2011; Müller and Riederer 2005). Moreover, for a polyphagous pest, a broader diet increases the risk of oviposition on the non-host or poor host along with host evaluation time in an ecological context (Chapman and Bernays 1989; Lucas-Barbosa et al. 2016; Müller and Hilker 2001).

The first physical contact between an herbivorous insect and the host plant occurs on the leaf surface and the epicuticular waxes act as volatile and structural cues towards host acceptance or rejection (Das et al. 2019; Debnath et al. 2021; Fernández et al. 2019; Eigenbrode and Espelie 1995; Jetter et al. 2000, 2006; Malik and Barik 2015; Müller 2006). The plant epicuticular waxes mainly consist of long-chain alkanes, free fatty acids (FFAs), esters, aldehydes, and primary and secondary alcohols, which composition varies widely within a species or cultivars of a species (Baker 1982; Jetter et al. 2006; Mitra et al. 2020; Roy et al. 2012a, b). The leaf epicuticular waxes play an important role in host recognition, oviposition, and feeding stimulants in different phytophagous insects (Li and Ishikawa 2006; Mitra et al. 2019; Roy 2019a, 2021b). The importance of plant leaf alkanes and FFAs as semiochemicals has been demonstrated for different insect species during the last three decades (Bernays and Champman 2000; Eigenbrode and Espelie 1995; Mitra et al. 2020; Parr et al. 1998; Roy 2021b; Sarkar et al. 2013a, b). Especially, low-volatile n-alkanes and FFAs have an important role in insect-plant interactions as an olfactory attractant (Karmakar et al. 2016; Malik et al. 2017; Mitra et al. 2019; Mobarak et al. 2020a; Roy et al. 2012a; Roy 2019a) and/or oviposition stimulant (Das et al. 2019; Li and Ishikawa 2006; Mitra et al. 2017; Parr et al. 1998; Udayagiri and Mason 1997).

To apply the chemical ecological approach, $S$. obliqua females, as well as their $5_{\text {th }}$ instar larvae, were tested in a series of bioassays for attraction, oviposition, and feeding preferences on the three potential host (three jute cultivars) plants in the present study. While numerous previous studies dealt with the attraction of different pest species to their host plant volatiles (Ikeura et al. 2010; Mitra et al. 2017, 2020, 2021; Mobarak et al. 2020a; Roy and Barik 2012b, 2014; Roy et al. 2012a), the comparative evidence for the complex host chemical properties used in navigation and oviposition site selection by $S$. obliqua has been scarce so far. According to Roy and Barik (2012a, 2013), Roy (2019a, 2019b, 2020), and Schoonhoven et al. (2005), polyphagous herbivores generally prefer to feed on mature leaves of their respective hosts. For this reason, epicuticular waxes of mature leaves of three fibre crops as host plants of $S$. obliqua were considered in this study. Even, there is currently no information about chemical cues mediated attraction, oviposition, and feeding preference in integration to $S$. obliqua to these host plants for an universal management strategy. The aims of the current research were (i) to identify and quantify the compositions of n-alkanes and FFAs present in the leaf epicuticular waxes of the three jute crops, (ii) to observe the variations in the composition of n-alkanes and FFAs between the fibre crops and in comparison with other crop plants, (iii) to interpret the role of leaf epicuticular wax chemistry and their analogous synthetic mixtures in short-range attraction (adult), oviposition (female), and feeding (5th instar larvae) of $S$. obliqua tested in different bioassays under laboratory conditions, (iv) to find out the most preferred n-alkanes and FFAs of leaf epicuticular wax, as well as their effective combinations in attraction, oviposition, and feeding of $S$. obliqua towards the design of a baited trap in future IPM strategies.

\section{Materials And Methods}

Plants: Three types ofjute crops such as, white jute (Corchorus capsularis, cv. JRC-80), tossa jute(C. olitorious, cv. JRO 204) and mesta jute or kenaf (Hibiscus cannabinus, cv. JRM 3) [Malvaceae] (Kumar et al. 2014, 2017; Mahapatra et al. 2009; Rahman and Khan 2012; Sarkar and Majumdar 2016) were cultivated in a field situated near Chinsurah Rice Research Center (CRRC), Chinsurah, $22^{\circ} 53^{\prime} \mathrm{N}, 88^{\circ} 23^{\prime} \mathrm{E}, 13 \mathrm{~m}$ above sea level (Hooghly, West Bengal, India) during their growing season in 2019-2021. Nine plots were prepared with an average number of plants per unit area of $30 \pm 4$ plants $\mathrm{m}^{-2}$ where each plot was of $10 \mathrm{~m} \times 10 \mathrm{~m}$ equipped with soil organic matter of $5.3 \pm 0.2 \%, \mathrm{pH} 7.7$, average relative humidity $(\mathrm{RH})$ of $70 \pm 5 \%$, and photoperiod of $13 \mathrm{~h} \mathrm{L:}: 11 \mathrm{~h}$ $\mathrm{D}$ at $30-34{ }^{\circ} \mathrm{C}$. The cultivated varieties (cvs) or cultivars were separately germinated and grown in three side-by-side plots with a distance of $0.5 \mathrm{~m}$ between two plots. A distance of $1 \mathrm{~m}$ was kept for the cultivation of each selected jute species and all plots were maintained without any insecticide. At the pre-flowering stage (8 to 10 week old) of each crop, 2 to 3 mature leaves (14 to 20 days old) leaving 4 to 5 tender leaves from the top were collected at $6 \mathrm{a}$. m. Three separate batches of ca. $100 \mathrm{~g}$ of leaves of each cultivar were collected from the plants in different plots for the extraction of leaf epicuticular waxes.

Page $3 / 21$ 
Insects: Using a light trap, S. obliqua adults (males and females) were collected from the field of cultivated sesame plants (Sesamum indicum cv. Rama Pedaliaceae) (Roy 2020), similarly grown like jute plants as mentioned above in a separate field near CRRC (West Bengal, India). The adults were placed in a nylon net cage $\left(40 \times 30 \times 30 \mathrm{~cm}^{3}\right)$ on the turgescent sesame leaves for egg-laying. Newly emerged first instar larvae $\left(L I, F_{1}\right)$ were kept on the same sesame leaves for feeding at $27 \pm 1^{\circ} \mathrm{C}, 70 \pm 10 \%$ $\mathrm{RH}$ and $12 \mathrm{~h} \mathrm{~L}: 12 \mathrm{~h}$ D photoperiod, and a light intensity of 1500 lux in a Biological Oxygen Demand (BOD) incubator (ADS, Kolkata, India) (Roy and Barik, 2013; Roy 2015a, b, 2017, 2019b, 2021a). Cut sesame leaf petioles were maintained in a moist piece of cotton wrapped with aluminium foil to prevent desiccation. Freshly cut leaves were provided replacing the wilting ones. Adults were fed with a $10 \%$ sucrose-in-tap-water solution soaked in cotton wool. Four generations $\left(F_{1}-F_{4}\right)$ of $S$. obliqua were completed on sesame leaves to avoid any pre-adaptation to the jute plants used in bioassays. The 1 to 2 days old gravid females $\left(F_{3}-F_{4}\right)$ were used for olfactory and oviposition bioassays, whereas 13-14-days old $5_{\text {th }}$ instar $\left(L V F_{4}\right)$ larvae were used for feeding bioassays on jute.

\section{Epicuticular wax analyses:}

Extraction of leaf epicuticular waxes: Freshly collected mature jute leaves (14 to 20 days old) of ca. $100 \mathrm{~g}$ fresh weight corresponding to $1.788 \pm 0.148,1.948 \pm 0.148$, and $1.248 \pm 0.148 \mathrm{~g} \mathrm{leaf}^{-1}$ (mean \pm SE) for white jute, tossa jute, and mesta jute, respectively (ESM Table 1), were dipped in $2 \mathrm{~L} \mathrm{n}$-hexane separately for $1 \mathrm{~min}$ at room temperature to extract the epicuticular wax which yielded slightly yellow extracts without traces of any chlorophyll (Mitra et al. 2020; Roy 2019a, 2021b). The crude extract was passed through filter paper Whatman No. 41 (Maidstone, UK), and hexane was evaporated at $27^{\circ} \mathrm{C}$ until the sample became dry. The extraction was repeated three times, separately for each jute cultivar. The dry extract (semisolid) wax weighed

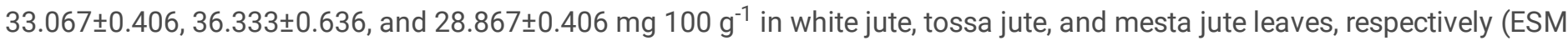
Table 1). Each crude extract was then dissolved in $40 \mathrm{ml} \mathrm{n}$-hexane and divided into four equal portions (equivalent to $25 \mathrm{~g}$ of leaves). The first one was used for the identification and quantification of n-alkanes and FFAs, whereas the second, third, and fourth ones were purified and used for olfactory attraction, oviposition, and feeding bioassays, respectively. All solvents used were of analytical grade and purchased from E. Merck (Mumbai, India). All standard n-alkanes and FAs (> 99\% purity) were purchased from Sigma-Aldrich (Darmstadt, Germany).

Identification and quantification of n-alkanes: One-half of the first portions of crude leaf extract of each jute cultivar was passed through a column of aluminum oxide (F-20 grade) and eluted with petroleum ether. The eluent was fractioned by Thin Layer Chromatography (TLC) on silica gel G (Sigma St. Louis, MO, USA) of $0.5 \mathrm{~mm}$ thickness by using carbon tetrachloride $\left(\mathrm{CCl}_{4}\right)$ as the mobile phase. A faint yellowish band appeared on the TLC plate and the plate was air-dried under laboratory conditions. The $\mathrm{R}_{f}$ (retardation factor) value (0.86) was compared with the $\mathrm{R}_{f}$ value of a mixture of synthetic n-alkanes between $n-C_{10}$ to $n-C_{40}$. The single hydrocarbon band produced in each TLC plate was eluted from the silica gel layer with chloroform, which showed only stretching C-H bonds in IR spectroscopy (JASCO FT-IR, spectrophotometer, Tokyo, Japan). The purified alkane samples were used for gas chromatography-mass spectrometry (GC-MS) and GC-FID (flame ionization detector) for identification and quantification, respectively (Roy 2019a, 2021b). The extracts were analyzed with a Shimadzu GCMS-QP5050A (Koyeto, Japan) to produce electron ionization (EI) mass spectra using HP-5MS column for GCMS-El analysis by using a specified oven temperature program: initially $80^{\circ} \mathrm{C}$ for $2 \mathrm{~min}$, then raised at $15^{\circ} \mathrm{C} \mathrm{min}-1$ to $320^{\circ} \mathrm{C}$, finally held for 15 min (Roy 2019a, 2021b). The volume of the injected sample was $1 \mu \mathrm{l}$ with a split ratio of $1: 10$. Identifications were made by comparison of spectra with library databases (NIST 2008) and also confirmed by comparison of their retention times (RTs) with those of standard n-alkanes $\left(n-C_{10}\right.$ to $\left.n-C_{40}\right)$ and the areas of each peak were converted into quantities of $n$-alkanes based on GC peak area of internal standard n-nonadecane ( $\mathrm{n}-\mathrm{C}_{19}$ at $100 \mathrm{ng} \mathrm{\mu l}^{-1}$ ) (Roy 2019a, 2021b).

Identification and quantification of FFAs: The remaining half of the first portions of the crude leaf extract of each jute cultivar was mixed with diethyl ether and filtered through Whatman No. 41 filter paper. The extract was purified by TLC on silica gel G of $0.5 \mathrm{~mm}$ thickness by using $\mathrm{n}$-butanol : acetic acid : water $(4: 1: 5)$ as the mobile phase after discarding water. The band $\left(\mathrm{R}_{f}\right.$ value of 0.78) was eluted from the silica gel layer with diethyl ether to get purified FFAs. Then, the purified FFAs were esterified with $3 \mathrm{ml} \mathrm{BF}_{3}-$ Methanol followed by warming for $5 \mathrm{~min}$ in a hot water bath at $50-60{ }^{\circ} \mathrm{C}$, and then cooled to $4{ }^{\circ} \mathrm{C}$. Hexane $(40 \mathrm{ml})$ was added to this mixture followed by washing with saturated $\mathrm{NaCl}$ twice in a separating funnel. The aqueous layer of each 
sample was discarded and the hexane fraction was passed through $40 \mathrm{~g}$ of anhydrous $\mathrm{Na}_{2} \mathrm{SO}_{4}$. The esterified FFAs samples were used for GC-MS and GC-FID for the identification and quantification, respectively (Roy 2019a, 2021b).The extracts were analyzed with a Shimadzu GCMS-QP5050A to produce electron ionization (EI) mass spectra using an HP-5MS column for GCMS-El analysis by setting a specified oven temperature program: initially at $120^{\circ} \mathrm{C}$ for $2 \mathrm{~min}$, then raised at the rate of $10{ }^{\circ} \mathrm{C} \mathrm{min}{ }^{-1}$ to $220^{\circ} \mathrm{C}$, and finally at $220^{\circ} \mathrm{C}$ for $15 \mathrm{~min}$ (Roy 2019a, 2021b). The volume of the injected sample was $1 \mu \mathrm{l}$ with a split ratio of 1:10. Identifications were made by the comparison of spectra with library databases (NIST 2008) and also confirmed by the comparison of their retention times (RTs) with those of methylated (esterified) standard FAs $\left(\mathrm{C}_{10: 0}\right.$ to $\left.\mathrm{C}_{24: 0}\right)$. The areas of each peak were converted into quantities of FFAs based on GC peak area of internal standard methyl tricosanoate $\left(\mathrm{C}_{23: 0}\right.$ at $100 \mathrm{ng} \mathrm{\mu l}^{-1}$ ) (Roy 2019a, 2021b).

\section{Bioassays:}

Chemicals:Both n-alkanes and FFAs isolated from leaf epicuticular waxes of the three jute cultivars were prepared in leaf equivalent $\left(\mu \mathrm{g}^{-1}\right.$ leaf $^{-1} \mathrm{ml}^{-1}$ ) amount dissolved in petroleum ether for different bioassays (olfaction, oviposition, and feeding). Petroleum ether was used as the control solvent because both adults and larvae were neither attracted nor deterred by it in preliminary bioassays. Individual synthetic n-alkanes, FFAs, and their mixtures mimicking the natural leaf wax $\left(\mu \mathrm{g}^{-1}\right.$ leaf $\left.^{-1} \mathrm{ml}^{-1}\right)$ were prepared in petroleum ether. The de-waxed leaves for the bioassay were prepared by dipping freshly cut mature leaves (14 to 20 days old) in $\mathrm{n}$-hexane for $1 \mathrm{~min}$ as described in the wax extraction paragraph above.

Insects:The $\mathrm{F}_{3}$ onward generations of $S$. obliqua larvae and adults were collected from the mass rearing for different bioassays in the laboratory condition at $27 \pm 1{ }^{\circ} \mathrm{C}, 60 \pm 5 \% \mathrm{RH}$, and light intensity of 1500 lux. Newly emerged, $1-2$ days old females were provisioned with water and starved for $12 \mathrm{~h}$ before use in the olfaction bioassay, and $10 \%$ sucrose solution was provided as food during the oviposition bioassay. Females were used in bioassay because they are responsible for finding a suitable site for oviposition by using different stimuli (visual, olfactory, tactile, and gustatory) for successful generations. The newly hatched $5_{\text {th }}$ instar larvae were provisioned with water and starved for $12 \mathrm{~h}$ before use for the feeding bioassay. Only $5_{\text {th }}$ instar larvae were used because they are most active and have the highest consumption rate among the instars. The larval bioassay was conducted to confirm the preference of the adult females in host plant selection to establish future generations. Females and $5_{\text {th }}$ instar larvae were selected and used once throughout the bioassays with three replications for each jute cultivar as described in Roy (2019a, 2021b).

Female olfaction: The effect of n-alkanes and FFAs as olfactory attractants was evaluated by different treatments under specified conditions (Roy et al. 2012a; Roy and Barik 2012b, 2014; Roy 2019a, 2021b). The behavioural responses of adult females were investigated in a Y-tube olfactometer: $10 \mathrm{~cm}$ long (I) stem and arms, $8 \mathrm{~cm}$ diameter (d), 60 $\mathrm{Y}$ angle (Roy 2019a, $2021 \mathrm{~b})$. The stem of the olfactometer was connected to a porous glass vial (d: $8.0 \mathrm{~cm} \times \mathrm{I}: 10.0 \mathrm{~cm})$ in which test insects were released. Each arm of the olfactometer was connected to a glass micro kit adapter (d: $4.0 \mathrm{~cm} \times \mathrm{I}: 6.0 \mathrm{~cm})$ fitted into a glass vial (d: $8.0 \mathrm{~cm} \times \mathrm{I}: 8.0 \mathrm{~cm}$ ). The aerator producing airflow of $450 \mathrm{ml} \mathrm{min}^{-1}$, which was first purified by passing through a charcoal filter and then adjusted to $150 \mathrm{ml} \mathrm{min}{ }^{-1}$ in left and right glass vials through the micro kit adapters. All the connections between different parts of the setup consisted of silicon tubes. One milliliter of the solvent containing one leaf equivalent $\left(\mu \mathrm{g} \mathrm{leaf}^{-1} \mathrm{ml}^{-1}\right)$ amount of identified n-alkanes and FFAs and their respective synthetic analogs were separately applied to Whatman no. 41 filter paper pieces $\left(2 \times 2 \mathrm{~cm}^{2}\right)$ as volatile sources, another one only with solvent (petroleum ether) as control, and allowed to evaporate the solvent in open space $(1 \mathrm{~min})$ under laboratory conditions. These filter papers were introduced into the glass vials attached to the olfactometer. One female of $S$. obliqua was introduced into the porous glass vial attached to the olfactometer (Roy 2019a, 2021b). The behavior of each female was observed for $3 \mathrm{~min}$ in the Y-tube. The increase in the observation time did not increase the number of responding insects. A threshold ("decision line") was located at the middle of each arm of the Y-tube, and an individual crossing the line within $3 \mathrm{~min}$ from the release point with at least half the body was counted as a response. If the line was not crossed within the observation time, the run was treated as no response. To eliminate traces from previous trials, the tube was cleaned with petroleum ether followed by acetone and dried in a hot air oven at $50{ }^{\circ} \mathrm{C}$ after 6 individuals were tested (Roy and Barik 2012b, 2014; Roy 2019a, 2021b). Each test with one volatile sample was conducted until a total of $72(24 \times 3)$ females had responded and after testing 12 insects while the position of the two arms was systematically changed (rotated 
$180^{\circ}$ ) to avoid any positional biases. The dual choice tests were conducted for the identified $20 \mathrm{n}$-alkanes (straight chain) and 14 FFAs individually in leaf equivalent $\left(\mu \mathrm{g} \mathrm{leaf}^{-1} \mathrm{ml}^{-1}\right.$ ) amounts present in respective jute cultivars to find the most preferred chemicals having a minimum $\geq 70 \%$ insect response (ESM Table 2). These most preferred synthetic n-alkanes $\left(n-C_{16}, n-C_{18}, n-\right.$ $\left.\mathrm{C}_{20}, \mathrm{n}-\mathrm{C}_{22}\right)$ and FFAs $\left(\mathrm{C}_{16: 1}, \mathrm{C}_{16: 0}, \mathrm{C}_{18: 0}, \mathrm{C}_{20: 0}, \mathrm{C}_{22: 0}\right)$ were used in mixture as well as in combination ( $4 \mathrm{n}$-alkanes $+5 \mathrm{FFAs}$ ) for all bioassays because they were more attractive than the individual compounds for all the jute species. Similar tests with natural $n-$ alkanes, FFAs, their mixtures (n-alkanes + FFAs) along with mixtures of most preferred synthetic 4 n-alkanes, 5 FFAs, their combined mixture ( 4 n-alkanes +5 FFAs) in leaf equivalent $\left(\mu \mathrm{g} \mathrm{leaf}^{-1} \mathrm{ml}^{-1}\right)$ amount, were conducted in the same manner as for synthetic individual compounds with three replications in different treatments under defined conditions as follows:

Condition 1. Alkanes-treated filter paper vs. solvent with 2 treatments such as total natural n-alkanes and a mixture of the most preferred synthetic 4 n-alkanes present in the three jute cultivars (ESM Table 3, Table 3).

Condition 2. FFA-treated filter paper vs. solvent with 2 treatments such as total natural FFAs and a mixture of the most preferred synthetic 5 FFAs present in the three jute cultivars (ESM Table 3, Table 3).

Condition 3. Combined-mixture-treated filter paper vs. solvent with 2 treatments such as total natural wax ( $\mathrm{n}$-alkanes + FFAs) and a mixture of the most preferred synthetic wax (4 n-alkanes + 5 FFAs) mixture present in the three jute cultivars (ESM Table 3 , Table 3).

Condition 4. Combined-synthetic-mixture-(4 n-alkanes + 5 FFAs)-treated leaf vs. solvent with 2 treatments such as intact leaf and de-waxed leaf of the three jute cultivars (ESM Table 3, Table 3).

The adult attraction index (Al\%) was determined for the above 8 treatments under 4 conditions using the formula: $[\{(\mathrm{T}-\mathrm{C}) /(\mathrm{T}+\mathrm{C})\}$ $\times 100$ ]; where, $T$ is the number of adult females attracted in various treatments (filter paper or jute leaf) and $C$ is the number of adult females attracted to solvent in the control (filter paper or jute leaf) with a few modifications (Singh et al. 2011; Roy 2021b).

Female oviposition: The oviposition preference was assessed by using 3 groups of 24 pairs of newly emerged male and female S. obliqua $\left(24 \times 3=72\right.$ pairs) kept in glass chambers $\left(40 \times 40 \times 40 \mathrm{~cm}^{3}\right)$. The natural and synthetic mixtures as in the adult olfaction bioassay were applied. The dual choice test was conducted for each treatment in the glass chambers covered with nylon net. The data were collected at a $24 \mathrm{~h}$ interval up to $96 \mathrm{~h}$. For the choice experiments, each jute leaf or filter paper was marked separating it into vertically oriented two halves. One half was treated with the test compound and the other half was kept as a control. Each mixture was applied with a micropipette in leaf equivalent ( $\mu \mathrm{gleaf}^{-1} \mathrm{ml}^{-1}$ ) amount present in the respective jute cultivars and after evaporating the solvent, one pair of newly emerged adult moths ( $1: 1$ sex ratio) were released in each glass chamber. Each chamber was provided with $10 \%$ sucrose solution as food and kept in a BOD incubator as used for mass culture. The jute leaf or filter paper sheet of the three replicates with eggs was taken out from the glass chamber and eggs were counted at the black head stage comparing the different treatments and conditions as in female olfaction bioassay (ESM Table 4, Table 4). The oviposition preference index (OPI \%) was determined for the 8 treatments under 4 conditions using the formula: $[\{(P-$ $\mathrm{Q}) /(\mathrm{P}+\mathrm{Q})\} \times 100$; where, $\mathrm{P}$ is the number of eggs laid at various treatments (leaf or filter paper) and $\mathrm{Q}$ is the number of eggs laid at control solvent (leaf or filter paper) with a few modifications (Singh et al. 2011; Roy 2021b).

Larval feeding: The larval feeding bioassay was conducted to trace the possible pairing between female oviposition preference and larval feeding choice. Freshly collected mature leaves of the three jute cultivars were tested for different treatments with intact vs. de-waxed leaves. The solvent on a de-waxed leaf was dried at $27 \pm 1{ }^{\circ} \mathrm{C}$ before the larvae were released onto the leaves. Fifth instar $\left(L V, F_{4}\right)$ larvae were selected for the experiment and placed separately in Petri dishes $(9 \mathrm{~cm}$ in diameter) with intact and de-waxed jute leaves for different treatments. Each treatment was replicated three times and conducted with $72(24 \times 3)$ larvae per replication, having 24 larvae in each group for each jute species. Leaf desiccation was prevented by covering the bottom of each Petri dish with wet filter paper. Larvae were allowed to feed for $24 \mathrm{~h}$ and the consumed area $\left(\mathrm{cm}^{2}\right)$ was measured for 6 different treatments under 3 defined conditions (Table 5) as in adult olfaction (condition 1, 2 and 4) bioassay (ESM Table 3 , Table 3). Conditions 1 and 2 were with the same treatments where filter paper were replaced by normal mature leaf of respective jute cultivars where as condition 3 were exclusively same as in adult olfaction (condition 4) bioassay (Table 5). The feeding index $(F \mid \%)$ was calculated for the 6 treatments under 3 conditions using the formula: $[(A-B) /(A+B)\} \times 100]$ where, $A$ and $B$ is the

Page 6/21 
area consumed from the intact or de-waxed leaf treated with wax chemicals or solvent with a few modifications (Singh et al. 2011; Roy 2021b).

Statistical analyses:The data on total amounts of n-alkanes and FFAs were analyzed by one-way ANOVA followed by Tukey's HSD test. The data obtained for responses of $S$. obliqua to jute leaf epicuticular wax compounds and mixtures of their synthetic analogs were analyzed by Chi-squire $\left(\chi^{2}\right)$ test based on the null hypothesis whether the ratio of individual choosing the stimulus vs. the control differed significantly from $1: 1$ (Zar 1999). Insects that did not respond to any one of the treatments were excluded from the analyses. All the statistical analyses were conducted by using the software SPSS 16.0 (SPSS Inc., Chicago, IL, USA).

\section{Results}

Leaf epicuticular wax chemistry:The $n$-hexane extracts of a single mature leaf $(n>52)$ of white jute $(1.788 \pm 0.148 \mathrm{~g}$, $\left.52.148 \pm 0.847 \mathrm{~cm}^{2}\right)$, tossa jute $\left(1.948 \pm 0.148 \mathrm{~g}, 58.726 \pm 0.794 \mathrm{~cm}^{2}\right)$, and mesta jute $\left(1.248 \pm 0.148 \mathrm{~g}, 47.581 \pm 0.746 \mathrm{~cm}^{2}\right)$ yielded $1064.175 \pm 83.481 \mu \mathrm{g}, 1187.578 \pm 70.683 \mu \mathrm{g}$, and $728.029 \pm 34.226 \mu \mathrm{g}$ epicuticular wax, respectively (ESM Table 1). Out of the extracted waxes from a single leaf of white jute, tossa jute, and mesta jute represented by $360.628 \pm 23.779 \mu \mathrm{g}, 451.570 \pm 21.825$ $\mu \mathrm{g}$, and $214.379 \pm 21.344 \mu \mathrm{g}$ of $\mathrm{n}$-alkanes and $75.741 \pm 3.594 \mu \mathrm{g}, 75.766 \pm 1.763 \mu \mathrm{g}$, and $55.500 \pm 4.660 \mu \mathrm{g}$ of FFAs, respectively, and remaining unidentified surface wax compounds (ESM Table 1). All the extracted n-alkanes and FFAs were differed significantly between the jute cultivars (one-way ANOVA, $F_{2,6} \geq 10.868, P \leq 0.010$ ) though their wax contents were without any significant (one-way ANOVA, $F_{2,6}=0.243, P=0.792$ ) differences (ESM Table 1).

Alkanes in the leaf epicuticular waxes:Total 27 different n-alkanes (20 straight chain +7 branched chain) were identified having chain lengths between $\mathrm{n}-\mathrm{C}_{14}$ to $\mathrm{n}-\mathrm{C}_{36}$ and further expressed in leaf equivalent ( $\mu \mathrm{g} \mathrm{leaf}^{-1}$ ) amount (Table 1). Among the 27 different n-alkanes, 25, 24, and 24 types of n-alkanes were identified from white jute, tossa jute, and mesta jute leaves, respectively (Table 1). Among them n-tetratriacontane $\left(n-C_{34}\right)$ was predominant $\left(144.397 \pm 6.971 \mu \mathrm{g} \mathrm{leaf}^{-1}\right)$ in tossa jute, whereas n-tetradecane $\left(n-C_{14}\right)$ was in lowest amount $\left(0.116 \pm 0.012 \mu\right.$ leaf $\left.^{-1}\right)$ in mesta jute (Table 1$)$. All the identified amounts of $n$ alkanes differed significantly between the jute cultivars (one-way ANOVA, $F_{2,6} \geq 20.501, P \leq 0.002$; Table 1 ).

FFAs in the leaf epicuticular waxes:Total 14 different FFAs were identified having chain lengths between $\mathrm{C}_{12: 0}$ to $\mathrm{C}_{22: 0}$ and further expressed in leaf equivalent ( $\mu$ g leaf $^{-1}$ ) amount (Table 2). Out of 14 different FFAs, 14, 13, and 13 types of FFAs were identified from white jute, tossa jute, and mesta jute leaves, respectively (Table 2). Among the FFAs, trihexadecanoin acid $\left(C_{16: 1}\right)$ was predominant $\left(37.034 \pm 0.848 \mu\right.$ g leaf $\left.^{-1}\right)$, whereas, heptadecanoic acid $\left(C_{17: 0}\right)$ was detected in lowest amount $(0.263 \pm 0.006 \mu \mathrm{g}$ leaf $^{-1}$ ) in tossa jute (Table 2). All the identified FFAs differed significantly between the jute cultivars as in n-alkanes (one-way ANOVA, $F_{2,6} \geq 18.793, P \leq 0.003 ;$ Table 2 ).

Female attraction by leaf epicuticular wax compounds:A series of olfactory bioassay (8 treatments under 4 defined conditions) were conducted to study the attraction index (Al\%) of $S$. obliqua females towards leaf cuticular wax chemicals (n-alkanes and FFAs) in comparison with most preferred respective synthetic analogs ( $4 \mathrm{n}$-alkanes and 5 FFAs) in leaf equivalent amount ( $\mu \mathrm{g}$ leaf $^{-1}$ ) present in the selected jute cultivars (ESM Table 3, Table 3).

Condition 1. Synthetic mixtures of the 4 n-alkanes $\left(n-C_{16}, n-C_{18}, n-C_{20}, n-C_{22}\right)$ were more preferred than the natural n-alkanes in all kinds of jute leaves, because of the presence of less preferred n-alkanes in natural mixtures (ESM Table 3, Table 3). The Al (\%) values for the synthetic mixtures at leaf equivalent $\left(\mu\right.$ leaf $\left.^{-1}\right)$ amounts $(133.508 \pm 3.727 \mu \mathrm{g}, 57.526 \pm 1.836 \mu \mathrm{g}$, and $17.317 \pm 2.835$ $\mu \mathrm{g}$, respectively) in white jute, tossa jute, and mesta jute were $18.982 \pm 2.370 \%, 14.815 \pm 2.137 \%$, and $10.648 \pm 2.095 \%$, respectively (Table 3).

Condition 2. Synthetic mixtures of the 5 FFAs $\left(C_{16: 1}, C_{16: 0}, C_{18: 0}, C_{20: 0}, C_{22: 0}\right)$ were more preferred to the natural FFAs in all kinds of jute leaves, because of the presence of less preferred FFAs in natural mixtures (ESM Table 3, Table 3). The AI(\%) values for the synthetic mixtures corresponding to leaf equivalent $\left(\mu \mathrm{g} \mathrm{leaf}^{-1}\right)$ amounts $(61.701 \pm 2.713 \mu \mathrm{g}, 62.251 \pm 1.603 \mu \mathrm{g}$, and $33.250 \pm 2.059$ 
$\mu \mathrm{g}$, respectively) in white jute, tossa jute, and mesta jute were $45.370 \pm 2.148 \%, 42.593 \pm 2.076 \%$, and $38.426 \pm 2.073 \%$, respectively (Table 3).

Condition 3. Synthetic combined mixtures ( 4 n-alkanes +5 FFAs) were preferred to the naturally combined mixtures ( $n$-alkanes + FFAs) in all kinds of jute leaves, because of less preferred n-alkanes and FFAs in natural mixtures (ESM Table 3, Table 3). The Al (\%) values for the synthetic-mixtures (4 n-alkanes+5 FFAs) corresponding to leaf equivalent ( $\mu$ leaf $\left.^{-1}\right)$ amounts $(195.209 \pm 2.950$ $\mu \mathrm{g}, 119.777 \pm 1.857 \mu \mathrm{g}$, and $50.567 \pm 3.508 \mu \mathrm{g}$, respectively) in white jute, tossa jute and mesta jute were $68.519 \pm 1.225 \%$, $66.667 \pm 1.389 \%$, and $62.963 \pm 2.816 \%$, respectively (Table 3 ).

Condition 4. The female Al (\%) were significantly $(P<0.05)$ higher for combined synthetic wax (4 n-alkanes +5 FFAs) mixtures treated intact leaves of white jute $(83.796 \pm 1.669 \%$ per $1259.384 \pm 72.213 \mu \mathrm{g}$ wax chemicals), tossa jute $(73.148 \pm 2.078 \%$ per $1307.355 \pm 66.820 \mu \mathrm{g}$ wax chemicals), and mesta jute $(77.315 \pm 4.560 \%$ per $778.596 \pm 29.359 \mu \mathrm{g}$ wax chemicals) compared to the de-waxed leaves of respective jute cultivars (Table 3 ).

The attraction (\%) to any of the treatments compared to the controls was always significantly higher (Chi-Square test, $\chi^{2} \geq 5.480$, $d f=1, P<0.05$ ), except for condition $1\left(\chi^{2} \leq 3.571, d f=1, P>0.05\right)$ (Table 3). All Al (\%) values were without any significant (oneway ANOVA, $F_{2,6} \leq 1.895, P \geq 0.230$ ) differences among the jute crops (Table 3 ). In all treatments, the Al (\%) values for the jute crops can be arranged in the order of white jute> tossa jute> mesta jute, and the comparison of means by Tukey's HSD test were also differ significantly in $\mathrm{Al}(\%)$ values $(P>0.05)$ with a few deviations (Table 3). The $\mathrm{Al}(\%)$ depending on the conditions ranged in the order of condition $4>$ condition $3>$ condition $2>$ condition 1 (ESM Table 3, Table 3). Among the treatments, the combinedsynthetic-mixture treated intact leaves showed the highest attractiveness because of the respective amounts of wax chemicals in the jute crops (ESM Table 3, Table 3).

Oviposition:The oviposition bioassays were conducted in a total of 8 treatments under 4 defined conditions to determine the OPI (\%) of S. obliqua (gravid females) as in adult olfaction for the selected jute cultivars (ESM Table 4, Table 4).

Condition 1. Synthetic mixtures of the 4 n-alkanes were more preferred than the natural $n$-alkanes present in the all jute crops as in adult olfaction (ESM Table 4, Table 4). OPI (\%) values for the synthetic mixtures at leaf equivalent ( $\mu \mathrm{g} \mathrm{leaf}^{-1}$ ) amounts (same as adult olfaction) in white jute, tossa jute, and mesta jute were $41.667 \pm 8.333 \%, 26.732 \pm 2.347 \%$, and $37.771 \pm 6.429 \%$, respectively (Table 4).

Condition 2. Similarly, synthetic mixtures of the 5 FFAs were more preferred than the natural FFAs present in the jute crops due to the same reasons as in adult olfaction (ESM Table 4, Table 4). OPI (\%) values for the synthetic mixtures at leaf equivalent ( $\mu \mathrm{g}$ leaf $^{-1}$ ) amounts (same as adult olfaction) in white jute, tossa jute, and mesta jute were $37.374 \pm 8.694 \%, 49.801 \pm 4.925 \%$, and $23.148 \pm 6.481 \%$, respectively (Table 4).

Condition 3. Synthetic combined mixtures ( 4 n-alkanes + 5 FFAs) were also more preferred than the natural wax mixture (nalkanes + FFAs) present in the jute crops due to the same reasons as in adult olfaction (ESM Table 4, Table 4). OPI (\%) values for the synthetic mixtures at leaf equivalent ( $\mu$ g leaf $^{-1}$ ) amounts (same as adult olfaction) in white jute, tossa jute, and mesta jute were $63.981 \pm 5.250 \%, 62.594 \pm 4.565 \%$, and $57.879 \pm 4.077 \%$, respectively (Table 4).

Condition 4. The OPI (\%) were significantly $(P<0.05)$ higher for combined synthetic wax $(4 n$-alkanes +5 FFAs $)$ mixtures treated intact leaves of white jute $(80.278 \pm 4.092 \%)$, tossa jute $(78.307 \pm 4.132 \%)$, and mesta jute $(69.167 \pm 3.632 \%)$ compared to the dewaxed leaves of respective jute cultivars at same leaf equivalent $\left(\mu \mathrm{g} \mathrm{leaf}^{-1}\right)$ amounts as in adult olfaction (Table 4).

The oviposition choice (\%) towards any of the treatments was always significantly higher than towards controls in condition 4 and combined synthetic wax ( $4 n$-alkanes +5 FFAs) mixtures in condition 3 (Chi-square test, $\left.\chi^{2} \geq 5.706, d f=1, P<0.05\right)($ Table 4). All the OPI (\%) values were without any significant (one-way ANOVA, $F_{2,6} \leq 2.243, P \geq 0.187$ ) differences between the jute crops except synthetic FFAs mixtures in condition 2 (one-way ANOVA, $F_{2,6}=7.034, P=0.027$ ) because all the crops were potent host plants for $S$. obliqua (ESM Table 4, Table 4). The OPI (\%) values for the jute crops can be arranged in the same order (white jute> tossa jute> mesta jute) as in adult olfaction, and the comparison of means by Tukey's HSD test were also differ 
significantly $(P>0.05)$ in OPI (\%) values with few deviations (Table 4). The OPI (\%) depending on the conditions ranged in the same order (condition 4 > condition $3>$ condition $2>$ condition 1) as in adult olfaction (ESM Table 4, Table 4). Among the treatments, the combined-synthetic-mixture-treated intact leaves showed the highest OPI (\%) because of the respective amounts of wax chemicals in the jute crops (Table 4).

Larval feeding:The choice test was conducted with $5^{\text {th }}$-instar larvae ( 6 treatments under 3 defined conditions) to find the larval $\mathrm{FI}$ (\%) towards leaf epicuticular wax chemicals ( $\mathrm{n}$-alkanes and FFAs) in leaf equivalent amount $\left(\mu \mathrm{g} \mathrm{leaf}^{-1}\right.$ ) present in the selected jute crops (Table 5).

Condition 1. Synthetic mixtures of the same $4 \mathrm{n}$-alkanes (most preferred in adult olfaction and oviposition) were more preferred than natural n-alkanes present in the jute crops because of the same reasons as in adults (Table 5). Similarly, larval FI (\%) for the synthetic mixtures ( 4 n-alkanes) at leaf equivalent amounts $\left(\mu \mathrm{g} \mathrm{leaf}^{-1}\right)$ in white jute, tossa jute, and mesta jute $(1197.683 \pm 15.610$ $\mu \mathrm{g}, 1245.104 \pm 13.503 \mu \mathrm{g}$, and $745.346 \pm 12.610 \mu \mathrm{g}$ wax chemicals, respectively) were $36.573 \pm 2.938 \%, 35.063 \pm 1.655 \%$, and $35.779 \pm 2.220 \%$, respectively (Table 5).

Condition 2. Synthetic mixtures of the 5 FFAs (most preferred in adult olfaction and oviposition) were more preferred than natural FFAs present in the jute crops because of the same reasons as in adults (Table 5). Similar to the results with adults, larval FI (\%) for the synthetic-mixtures (5 FFAs) at leaf equivalent amounts ( $\mu \mathrm{g} \mathrm{leaf}^{-1}$ ) in white jute, tossa jute, and mesta jute $(1125.876 \pm 12.713 \mu \mathrm{g}, 1249.829 \pm 11.603 \mu \mathrm{g}$, and $761.279 \pm 12.106 \mu \mathrm{g}$ wax chemicals, respectively) were $37.550 \pm 3.863 \%$, $36.382 \pm 2.773 \%$, and $36.715 \pm 3.075 \%$, respectively (Table 5).

Condition 3. Combined-synthetic-mixtures ( 4 n-alkanes + 5 FFAs) treated intact leaves were more preferred than de-waxed leaves of the jute crops due to the same reasons as demonstrated for the adults (Table 5). Similar to results obtained with adults, the larval $\mathrm{Fl}(\%)$ values for the synthetic mixtures (4 n-alkanes $+5 \mathrm{FAs})$ at same leaf equivalent $\left(\mu \mathrm{g} \mathrm{leaf}^{-1}\right)$ amounts of respective jute crops as in condition 4 of adult olfaction as well as oviposition tests were $38.854 \pm 5.163 \%, 36.452 \pm 2.827 \%$, and $37.952 \pm 4.276 \%$, respectively (Table 5).

The larval feeding (\%) towards all treatments were always without significant (Chi-square test, $\chi^{2} \leq 3.537, d f=1, P>0.05$ ) differences due to presence of potent host leaves in all treatments (Table 5). All the FI (\%) values did not differ significantly (oneway ANOVA, $F_{2,6} \leq 0.270, P \geq 0.772$ ) among the jute crops (Table 5). The $\mathrm{FI}(\%)$ values for the jute crops can be arranged in the order of white jute> mesta jute> tossa jute and the comparison of means by Tukey's HSD test were also differ significantly $(P>$ 0.05) in $\mathrm{FI}(\%)$ values with few deviations due to different phytoconstituents of the respective jute leaves (Table 5). The $\mathrm{FI}$ (\%) depending on the conditions ranged in the same order (condition $3>$ condition $2>$ condition 1 ) like adults (Table 5). Among the treatments, the combined-synthetic-mixture-treated intact leaves showed the highest FI (\%) because of the respective amounts of preferred wax chemicals as well as other phytochemical regime in the respective jute crops (Table 5).

Considering all the above bioassays experiments (olfaction, oviposition, and larval feeding), the most stimulating synthetic combination mixture was represented by 4 n-alkanes and 5 FFAs in mature leaf equivalent $\left(\mu \mathrm{g}\right.$ leaf $\left.{ }^{-1}\right)$ amounts of all the selected jute cultivars.

\section{Discussions}

The leaf surface of the selected fibre crops represents different patterns of epicuticular wax deposition as in other studies (Debnath et al. 2021; Jetter et al. 2000; Kim et al. 2009; Kumari 2020; Roy et al. 2012b; Silva et al. 2017; Roy 2019a). These surface characteristics of the jute leaves were provided olfactory and tactile stimuli for suitable oviposition site selection by $S$. obliqua like other lepidopterans such as, Amyelois transitella Walker, Choristoneura fumiferana Clemens, Ostrinia nubilalis Hübner, Diacrisia casignetum Kollar, Helicoverpa armigera Hübner, Spodoptera litura Fabricius, etc. (Grant et al. 2000; Li and Ishikawa 2006; Phelan et al. 1991; Roy 2019a, 2021b; Udayagiri and Mason 1997). In total, 27 types of n-alkanes from n- $\mathrm{C}_{14}$ to n-

$\mathrm{C}_{36}$ (20 straight chain +7 branched chain) and 14 types of FFAs (11 saturated +3 unsaturated) from $\mathrm{C}_{12: 0}$ to $\mathrm{C}_{22: 0}$ were detected in the leaf epicuticular wax of the three jute crops (white jute, tossa jute, and mesta jute) as major components with significant 
variations in their respective quantity $\left(\mu \mathrm{g} \mathrm{leaf}^{-1}\right)$. These findings are similar to previous reports for other plants like, Vigna radiata (L.) R. Wilczek (Fabaceae), Sesamum indicum (Pedaliaceae), Momordica charantia (L.) (Cucurbitaceae), M. cochinchinensis (Lour.) (Cucurbitaceae), Ludwigia adscendens (L.) H. Hara (Onagraceae), L. octavalvis (Jacq.) P.H. Raven (Onagraceae), Polygonum orientale (L.) (Polygonaceae), Lathyrus sativus (L.) (Fabaceae), etc. (Malik and Barik 2015; Mitra et al. 2017; Mobarak et al. 2020a; Mukharjee et al. 2014; Roy et al. 2012a; Roy, 2021b; Sarkar et al. 2013a, b). Among the identified n-alkanes and FFAs of the studied jute crops, $n-C_{34}\left(144.397 \pm 6.971 \mu\right.$ leaf $\left.^{-1}\right)$ and $C_{16: 1}\left(37.034 \pm 0.848 \mu\right.$ leaf $\left.^{-1}\right)$ of tossa jute leaf were most abundant. Previous studies suggested that various n-alkanes and FFAs were predominated in the leaf epicuticular waxes of various plant species (Das et al. 2019; Debnath et al. 2021; Karmakar et al. 2016; Li and Ishikawa 2006; Malik et al. 2015, 2017; Mukherjee et al. 2014, 2015; Mobarak et al. 2020a; Roy 2021b). Variations in the composition of leaf epicuticular wax compounds occur between plant species and even within different cultivars (Debnath et al. 2021; Jetter et al. 2000; Mitra et al. 2020; Mobarak et al. 2020a; Roy 2021b; Wang et al. 2015). Leaf surface wax of Fatsia japonica (Thunb.) Decne. \& Planch. (Araliaceae) revealed the presence of $18 \mathrm{n}$-alkanes from $n-C_{16}$ to $n-C_{33}$ and 14 FFAs from $C_{9: 0}$ to $C_{22: 0}$, where $n-C 19$ and $C 16: 0$, respectively, were most abundant ( $\mathrm{Li}$ and Ishikawa 2006). Epicuticular wax of mature sunflower ( $H$. annuus cv. PAC-36) leaves contained 9 n-alkanes ( $n-C_{24}$ to $\left.n-C_{33}\right)$ and 13 FFAs $\left(C_{12: 0}\right.$ to $\left.C_{20: 0}\right)$ where, $n-C_{29}$ and $C_{18: 2}$, respectively were most predominant (Roy and Barik 2012b, 2014). Whereas, in M. charantia L. (Cucurbitaceae) 20 n-alkanes ( $n-C_{15}$ to $n-C_{36}$ ) were identified and $n-C_{33}$ was predominant (Sarkar et al. 2013a). Mature leaf surface wax of M. cochinchinensis Spreng (Cucurbitaceae) revealed the presence of $20 \mathrm{n}$-alkanes ( $\mathrm{n}-\mathrm{C}_{15}$ to $\mathrm{n}-\mathrm{C}_{35}$ ) (Mukherjee et al. 2015). In creeping cucumber, Solena amplexicaulis (Lam.), leaf surface waxes revealed $18 \mathrm{n}$-alkanes $\left(n-C_{15}\right.$ to $\left.n-C_{36}\right)$ and 14 FFAs $\left(C_{12: 0}\right.$ to $\left.C_{22: 0}\right)$ (Karmakar et al. 2016). Mature leaf surface waxes of $P$. orientale L. (Polygonaceae) weed revealed 19 n-alkanes $\left(n-C_{15}\right.$ to $\left.n-C_{33}\right)$ and 15 FFAs $\left(C_{12: 0}\right.$ to $\left.C_{21: 0}\right)$ (Malik et al. 2015 , 2017). Whereas, two rice-field weeds, Commelina benghalensis L. and Murdannia nudiflora (L.) revealed $20 \mathrm{n}$-alkanes $\left(\mathrm{C}_{14}\right.$ to $C_{36}$ ) and 13 FFAs $\left(C_{12: 0}\right.$ to $\left.C_{22: 0}\right)$ where, $n-C_{15}$ and $C_{16: 1}$ were predominant (Das et al. 2019). In the leaf surface wax of grass pea, L. sativus L. cv. Nirmal B-1 and BIO L 212, (Fabaceae) total, 18 n-alkanes (n- $C_{15}$ to $\left.n-C_{36}\right)$ and 14 FFAs $\left(C_{12: 0}\right.$ to $\left.C_{22: 0}\right)$ were detected where, $n-C_{15}$ and $C_{16: 1}$, respectively, were most predominant (Mitra et al. 2020). In green gram ( $V$. radiata cv. PDM) $20 \mathrm{n}$ alkanes ( $\mathrm{n}-\mathrm{C}_{15}$ to $\left.\mathrm{n}-\mathrm{C}_{36}\right)$ and 13 FFAs $\left(\mathrm{C}_{12: 0}\right.$ to $\left.\mathrm{C}_{21: 0}\right)$ were identified from their leaf cuticular wax and among them n- $\mathrm{C}_{25}$ and $\mathrm{C}_{16: 1}$, respectively were most abundant (Mobarak et al. 2020a). Leaf cuticular wax of sesame ( $S$. indicum, cv. Savitri and Nirmala) indicated the presence of $14 \mathrm{n}$-alkanes $\left(n-C_{9}\right.$ to $\left.n-C_{44}\right)$ and 12 FFAs $\left(C_{9: 0}\right.$ to $\left.C_{20: 0}\right)$ where, $n-C_{26}$ and $C_{18: 1}$, respectively were most predominant (Roy 2021b). Moreover, 20 n-alkanes ( $n-C_{14}$ to $n$ - $\left.C_{36}\right)$ and 13 FFAs $\left(C_{12: 0}\right.$ to $\left.C_{21: 0}\right)$ were detected in the leaf surface waxes of three Trichosanthes anguina L. cultivars (MNSR-1, Baruipur Long, and Polo No.1) and among them n- $\mathrm{C}_{17}$ and $\mathrm{C}_{18: 0}$ were predominant (Debnath et al. 2021). Similarly, leaf surface wax of white jute (C. capsularis cv. Sonali [JRC-321]) contain 18 n-alkanes ( $n-C_{16}$ to $n-C_{36}$ ) and 13 FFAs $\left(C_{12: 0}\right.$ to $C_{20: 0}$ ) and among them $n-C_{29}$ and $C_{18: 1}$, respectively, were most abundant (Roy 2019a). Moreover, the above-mentioned n-alkanes and FFAs can act as short-range attractants as well as other behavioural responses for different insect pests of respective host plants (Das et al. 2019; Debnath et al. 2021; Karmakar et al. 2016; Li and Ishikawa 2006; Malik and Barik 2015, 2017; Mitra et al. 2017, 2019, 2020; Mobarak et al. 2020a; Roy 2019a, 2021b)

The short-distance behavioural responses of different insects have been previously evaluated through different olfactometers ( $V$ shaped, multi-tube, six-arm, Y-tube, etc. (Koschier et al. 2000; Mitra et al. 2020; Roy, 2019a; Turlings et al. 2004). The Y-tube olfactometer used in present bioassays revealed clear olfactory responses of $S$. obliqua females to n-alkanes and FFAs present in leaf waxes of three fibre crops. After reaching near the host plant, n-alkanes and FFAs acted as short-range attractants which also facilitated feeding induction in the larvae and oviposition in gravid females of $S$. obliqua. In other instances, two FFAs ( $\mathrm{C}_{18: 1}$, $\mathrm{C}_{18: 2}$ ) act as host finding and oviposition cues for the navel orange worm, Amyelois transitella (Walker) (Lepidoptera, Pyralidae) (Phelan et al. 1991). Similarly, FFAs from $\mathrm{C}_{8: 0}$ to $\mathrm{C}_{12: 0}, \mathrm{C}_{18: 1}$ and $\mathrm{C}_{18: 2}$ in the epicuticular waxes of Picea and Abies spp. were also served as oviposition stimulants for the spruce budworm Choristoneura fumiferana (Clemens) (Lepidoptera, Tortricidae) (Grant et al. 2000). Whereas, 5 long-chain n-alkanes $\left(n-C_{26}\right.$ to $n-C_{30}$ ) present in the epicuticular wax of corn Zea mays $L$. (Poaceae) and Japanese knotweed Fallopia japonica (Houtt.) Ronse Decr. (Polygonaceae) leaves act as oviposition stimulants in the European corn borer, Ostrinia nubilalis (Hübner) (Lepidoptera, Pyralidae) (Li and Ishikawa 2006; Udayagiri and Mason 1997). Synthetic blend of 5 n-alkanes $\left(n-C_{18}, n-C_{23}, n-C_{24}, n-C_{28}\right.$, and $\left.n-C_{32}\right)$ and 6 FFAs $\left(C_{16: 0}, C_{16: 1}, C_{18: 0}, C_{18: 1}, C_{18: 2}\right.$, and $\left.C_{18: 3}\right)$ in sunflower leaf equivalent amount attracted the arctiid moth, D. casignetum (Roy and Barik 2012b, 2014). A synthetic blend of 9 n-alkanes (n- 
$\mathrm{C}_{19-21}, \mathrm{n}-\mathrm{C}_{25-26}, \mathrm{n}-\mathrm{C}_{28-29}, \mathrm{n}-\mathrm{C}_{31}$ and $\mathrm{n}-\mathrm{C}_{33}$ ) at $M$. charantia leaf equivalent amount was most attractive to the female insect, Epilachna dodecastigma (Wied.) (Sarkar et al. 2013a). A synthetic blend of 4 n-alkanes $\left(n-C_{19}, n-C_{31}, n-C_{33}, n-C_{35}\right)$ and 4 FFAs $\left(C_{14: 0}, C_{16: 1}, C_{18: 1}, C_{19: 0}\right)$ in leaf equivalent amount of $M$. cochinchinensis, respectively showed highest attraction to female Aulacophora foveicollis Lucas (Coleoptera: Chrysomelidae) (Mukherjee et al. 2014, 2015). Similarly, A. foveicollis Lucas displayed highest attraction to a synthetic mixture of $\mathrm{n}-\mathrm{C}_{15}, \mathrm{n}-\mathrm{C}_{29}, \mathrm{C}_{16: 0}, \mathrm{C}_{18: 0}, \mathrm{C}_{18: 3}$ at leaf equivalent amount of $S$. amplexicaulis (Karmakar et al. 2016). The rice-field weed, L. adscendens L. (Onagraceae) leaves revealed 3 prevailing saturated fatty acids (i.e., $\mathrm{C}_{14: 0}, \mathrm{C}_{16: 0}$, and $\mathrm{C}_{18: 0}$ ) in attraction of a flea beetle, Altica cyanea (Weber) (Coleoptera: Chrysomelidae), females at different concentrations (Roy et al. 2012a). Similarly, the flea beetle (A. cyanea) also showed attraction and oviposition to a synthetic blend of $\mathrm{n}-\mathrm{C}_{16}, \mathrm{n}-\mathrm{C}_{18}, \mathrm{n}-\mathrm{C}_{20}, \mathrm{n}-\mathrm{C}_{23}, \mathrm{C}_{16: 0}, \mathrm{C}_{18: 3}$, in 0.25 mature leaf equivalent surface waxes of L. octovalvis (Jacq.) Raven (Onagraceae) (Mitra et al. 2017). A synthetic blend of 10 n-alkanes $\left(n-C_{16-18}, n-C_{20-21}, n-C_{23-24}, n-C_{26}, n-C_{28}, n-C_{31}\right)$ and 7 FFAs $\left(C_{12: 0}, C_{14: 0}, C_{15: 0}, C_{16: 1}, C_{17: 0}, C_{19: 0}, C_{20: 0}\right)$ at leaf equivalent amount of $P$. orientale $L$. indicated highest attraction of the insect, Galerucella placida Baly (Coleoptera: Chrysomelidae) (Malik et al. 2015, 2017). Even, a synthetic blend of $4 \mathrm{n}$-alkanes ( $\left(\mathrm{n}-\mathrm{C}_{22-23}\right.$, $\left.\mathrm{n}-\mathrm{C}_{25}, \mathrm{n}-\mathrm{C}_{27}\right)$ and 4 FFAs $\left(\mathrm{C}_{13: 0}, \mathrm{C}_{16: 1}, \mathrm{C}_{18: 2}, \mathrm{C}_{20: 0}\right)$ in leaf equivalent amount of $C$. benghalensis and $M$. nudiflora, respectively served as short-range attractant and oviposition stimulant in Lema praeusta (Fab.) (Coleoptera: Chrysomelidae). (Das et al. 2019). In the grass pea, $L$. sativus $L$., 5 n-alkanes $\left(n-C_{15}, n-C_{22}, n-C_{25}, n-C_{27}, n-C_{33}\right)$ and 2 FFAs $\left(C_{13: 0}, C_{18: 2}\right)$ in mixture acted as attractants and stimulated the emergence of nymphs in Aphis craccivora Koch (Hemiptera: Aphididae) at leaf equivalent amount (Mitra et al. 2020). Even, olfactory attraction, oviposition and feeding preference of 3 generalist pests (S. obliqua Walker, Helicoverpa armigera Hübner, and Spodoptera litura Fabricius) were maximum towards the combined mixture of $4 \mathrm{n}$-alkanes ( $\mathrm{n}$ $\left.\mathrm{C}_{16}, \mathrm{n}-\mathrm{C}_{22}, \mathrm{n}-\mathrm{C}_{24}, \mathrm{n}-\mathrm{C}_{26}\right)$ and 3 FFAs $\left(\mathrm{C}_{12: 0}, \mathrm{C}_{14: 0}, \mathrm{C}_{18: 1}\right)$ in sesame (cv. Savitri) leaf equivalent amount (Roy, 2021b). Moreover, a synthetic blend of $\mathrm{n}-\mathrm{C}_{17}, \mathrm{n}-\mathrm{C}_{20}, \mathrm{n}-\mathrm{C}_{26}$ and $\mathrm{C}_{18: 0}$ in one leaf equivalent surface wax of $T$. anguina $\mathrm{L}$. (cv. MNSR-1) was acted as short-range attractants and oviposition stimulants in Diaphania indica (Lepidoptera, Crambidae) (Debnath et al. 2021). Whereas, a synthetic combined mixture of 4 n-alkanes $\left(n-C_{17}, n-C_{18}, n-C_{27}, n-C_{29}\right)$ and $5 F F A s\left(C_{16: 0}, C_{16: 1}, C_{18: 1}, C_{18: 2}, C_{18: 3}\right)$ in white jute $(C$. capsularis $\mathrm{cv}$. Sonali [JRC-321]) leaf equivalent amount was most attractive to $D$. casignetum adults, whereas the same mixture excluding 2 n-alkanes ( $\mathrm{n}-\mathrm{C}_{27}, \mathrm{n}-\mathrm{C}_{29}$ ) also caused a signi $\square$ cant oviposition preference (Roy 2019a).

Similarly, in the present study, 4 -alkanes $\left(n-C_{16}, n-C_{18}, n-C_{20}, n-C_{22}\right)$ and 5 FFAs $\left(C_{16: 1}, C_{16: 0}, C_{18: 0}, C_{20: 0}, C_{22: 0}\right)$ in a combined mixture at leaf equivalent ( $\mu \mathrm{g} \mathrm{g}{ }^{-1}$ leaf) amounts $(195.209 \pm 2.950 \mu \mathrm{g}, 119.777 \pm 1.857 \mu \mathrm{g}$, and $50.567 \pm 3.508 \mu \mathrm{g}$, respectively) in white jute, tossa jute, and mesta jute, respectively acted as short-range olfactory attractants, oviposition stimulants and larval feeding stimulant in $S$. obliqua. The most stimulating synthetic combination mixture was represented by $4 \mathrm{n}$-alkanes $(133.508 \pm 3.727 \mu \mathrm{g})$ containing $\mathrm{n}-\mathrm{C}_{16}(27.254 \pm 1.801 \mu \mathrm{g}), \mathrm{n}-\mathrm{C}_{18}(40.741 \pm 2.692 \mu \mathrm{g}), \mathrm{n}-\mathrm{C}_{20}(35.993 \pm 2.378 \mu \mathrm{g}), \mathrm{n}-\mathrm{C}_{22}(29.520 \pm 1.950$ $\mu \mathrm{g})$, and 5 FFAs $(61.701 \pm 2.713 \mu \mathrm{g})$ containing $\mathrm{C}_{16: 1}(24.846 \pm 1.167 \mu \mathrm{g}), \mathrm{C}_{16: 0}(14.801 \pm 0.695 \mu \mathrm{g}), \mathrm{C}_{18: 0}(1.628 \pm 0.076 \mu \mathrm{g}), \mathrm{C}_{20: 0}$ $(3.938 \pm 0.185 \mu \mathrm{g}), \mathrm{C}_{22: 0}(16.488 \pm 0.775 \mu \mathrm{g})$ at leaf equivalent $\left(\mu \mathrm{g} \mathrm{leaf}^{-1}\right)$ amount present in mature white jute leaves. Moreover, this combined-synthetic-mixture (4 n-alkanes +5 FFAs [195.209 $\left.\pm 2.950 \mu \mathrm{g} \mathrm{leaf}^{-1}\right]$ ) treated intact white jute leaves (mature) showed highest adult Al (\%), OPI (\%), and larval FI (\%) of $83.796 \pm 1.669 \%, 80.278 \pm 4.092 \%$, and $38.854 \pm 5.163 \%$, respectively, over the other treatments as well as other jute crops. Similarly, Mobarak et al. (2020a) recorded that females of $S$. obliqua were attracted towards a synthetic blend of 4 n-alkanes $\left(n-C_{25}, n-C_{27}, n-C_{29}, n-C_{36}[176.7 \mu g]\right)$ and 3 FFAs $\left(C_{16: 1}, C_{18: 0}, C_{18: 3}[43.2 \mu g]\right)$ present in the leaf surface waxes of green gram (cv. PDM). Moreover, this combined-synthetic-mixture (4 n-alkanes +5 FFAs [195.209 $\left.\pm 2.950 \mathrm{\mu g} \mathrm{leaf}^{-1}\right]$ ) treated intact white jute leaves (mature) showed highest adult Al (\%), OPI (\%), and larval FI (\%) of $83.796 \pm 1.669 \%, 80.278 \pm 4.092 \%$, and $38.854 \pm 5.163 \%$, respectively, over the other treatments as well as other jute crops.

Thus, this finding can explain how the $S$. obliqua females choose oviposition sites on their potential hosts (white jute> tossa jute> measta jute) by using different sensory modalities [visual (shape and colour), olfactory (n-alkanes and FFAs as semiochemicals), tactile (leaf surface ultrastructure), and gustatory (leaf surface wax)] towards a better survival and growth of their neonates, as reported for other insects (Carlsson et al. 1999; Mitra et al. 2017, 2019, 2020; Roy 2019a, 2021b). The behavioural responsiveness of the gravid females was also comparable to that of larval feeding preferences. According to preference performance hypothesis (PPH), S. obliqua females maximize the population fitness by laying eggs on their preferred host plants (white jute> tossa jute> measta jute) where their offspring perform best like other butterflies and moths (Birke and 
Aluja 2018; Roy 2019a; Griese et al. 2020). So, the present study suggests that the synthetic blends of $4 n$-alkanes (n-C $C_{16}, n-C_{18}$,

$\left.\mathrm{n}-\mathrm{C}_{20}, \mathrm{n}-\mathrm{C}_{22}\right)$ and 5 FFAs $\left(\mathrm{C}_{16: 1}, \mathrm{C}_{16: 0}, \mathrm{C}_{18: 0}, \mathrm{C}_{20: 0}, \mathrm{C}_{22: 0}\right)$ of respective jute crops can be used as lures to develop baited traps as a promising method for IPM of $S$. obliqua. Further, the study also supports to reduce indiscriminate use of any usual chemical control measures for sustainable management of $S$. obliqua for successful jute cultivation in the near future.

\section{Declarations}

Funding: West Bengal Department of Science and Technology (WBDST) Project [File No.: ST/P/S\&T/1G-29/2018], from Government of West Bengal, India

Competing interests: The authors have no relevant financial or non-financial interests to disclose.

Author's contributions: NR designed the whole study including sample collection, chemical analysis with the help of another author SHM, index calculation, data analysis and drafts the manuscript with the help of institutional support.

Acknowledgments I wish to express my deep sense of gratitude to West Bengal Department of Science and Technology (WBDST) Project [File No.: ST/P/S\&T/1G-29/2018], from Government of West Bengal, India, for financial assistance. I must acknowledge the farmers who help me in every way during jute cultivation and pest collection.

\section{References}

1. Aartsma Y, Bianchi F, Werf W, Poelman E, Dicke M (2017) Herbivore induced plant volatile and tritrophic interactions across spatial scales. New Phytol 216(4): 1054-1063. https://doi.org/10.1111/nph.14475

2. Aktar MW, Sengupta D, Chowdhury A (2009) Impact of pesticides use in agriculture: their benefits and hazards. Interdiscip Toxicol 2(1):1-12. https://doi.org/10.2478/v10102-009-0001-7

3. Baker EA (1982) Chemistry and morphology of plant epicuticular waxes. In: Cutler DF, Alvin KL, Price CE (ed) The plant cuticle. Academic Press, London, pp 139-165

4. Barragán-fonseca K, Vanloon JA, Dicke M, Lucas-Barbosa D (2020) Use of visual and olfactory cues of flowers of two brassicaceous species by insect pollinators. Ecol Entomol 45: 45-55. https://doi.org/10.1111/een.12775

5. Bernays EA, Chapman RF (2000) Plant secondary compounds and grasshoppers: beyond plant defenses. J Chem Ecol 26:1773-93. https://doi.org/10.1023/A:1005578804865

6. Bhadauria NKS, Bhadauria NS, Jakhmola SS (2001) Larval development and survival of Bihar hairy caterpillar, Spilosoma obliqua (Walk.) on different host plants. Ind J Entomol 63:475-477

7. Birke A, Aluja M (2018) Do mothers really know best? Complexities in testing the preference-performance hypothesis in polyphagous frugivorous fruit flies. Bull Entomol Res 108(5):674-684. https://doi.org/10.1017/s0007485317001213

8. Carlsson MA, Anderson P, Hartlieb E, Hansson BS (1999) Experience-dependent modification of orientational response to olfactory cues in larvae of Spodoptera littoralis. J Chem Ecol 25: 2445-2454. https://doi.org/10.1023/A:1020865922827

9. Carvalho FP (2017) Pesticides, environment, and food safety. Food Ener Secur 6(2):48-60

10. Chapman RF (2003) Contact chemoreception in feeding by phytophagous insects. Annu Rev Entomol 48: 455-484

11. Chapman RF, Bernays EA (1989) Insect behavior at the leaf surface and learning as aspects of host plant selection. Cellular Mol Life Sci 45: 215-222

12. Dahanukar A, Hallen EA, Carlson JR (2005) Insect chemoreception. Curr Opin Neurobiol 15: 423-430. https://doi.org/10.1016/j.conb.2005.06.001

13. Das S, Koner A, Barik A (2019) A beetle biocontrol agent of rice field weeds recognizes its host plants by surface wax longchain alkanes and free fatty acids. Chemoecol 29: 155-170. https://doi. org/10.1007/s0004 9-019-00285 -1

14. Debnath R, Mitra P, Das S, Barik A (2021) Leaf surface wax chemicals in Trichosanthes anguina (Cucurbitaceae) cultivars mediating short-range attraction and oviposition in Diaphania indica. J Chem Ecol https://doi. org/10.1007/s10886-02101291-w

Page $12 / 21$ 
15. Eigenbrode SD, Espelie KE (1995) Effects of plant epicuticular lipids on insect herbivores. Annu Rev Entomol 40: 171-194. https://doi.org/10.1146/annurev.en.40.010195.001131

16. Feng B, Qian K, Du YJ (2017) Floral volatiles from Vigna unguiculata are olfactory and gustatory stimulants for oviposition by the bean pod borer moth Maruca vitrata. Insects 8(2):60. https://doi.org/10.3390/insects8020060

17. Fernández PC, Braccini CL, Dávila C, Barrozo RB, Aráoz MVC, Cerrillo T, Gershenzon J, Reichelt M, Zavala JA (2019) The use of leaf surface contact cues during oviposition explains field preferences in the willow sawfly Nematus oligospilus. Sci Reports 9: 4946. https://doi. org/10.1038/s4159 8-019-41318 -7

18. Foster SP, Howard AJ (1998) Influence of stimuli from Camellia japonica on ovipositional behavior of generalist herbivore Epiphyas postvittana. J Chem Ecol 24: 1251-1275. https://doi.org/10.1023/A:1022455120922

19. Gotyal BS, Selvaraj K, Meena PN, Satpathy S (2015) Host plant resistance in cultivated jute and its wild relatives towards jute hairy caterpillar Spilosoma obliqua (Lepidoptera: Arctiidae). Florida Entomol 98(2): 721-727. https://doi.org/10.1653/024.098.0248

20. Goyret J, Markwell PM, Raguso RA (2007) The effect of olfactory and visual stimuli decoupling on the foraging behavior of Manduca sexta. J Exp Biol 210: 1398-1405

21. Grant GG, Zhao B, Langevin D (2000) Oviposition response of spruce budworm (Lepidoptera: Tortricidae) to aliphatic carboxylic acids. Environ Entomol 29(2):164-170. https://doi.org/10.1093/ee/29.2.164

22. Griese E, Pineda A, Pashalidou FG, Iradi EP, Hilker M, Dicke M, Fatouros NE (2020) Plant responses to butterfly oviposition partly explain preference-performance relationships on different brassicaceous species. Oecologia 192:463-475. https://doi.org/10.1007/s00442-019-04590-y

23. Ikeura H, Kobayashi F, Hayata Y (2010) How do Pieris rapae search for Brassicaceae host plants? Biochem Syst Eco/38(6): 1199-1203. https://doi.org/10.1016/j.bse.2010.12.007

24. Jetter R, Kunst L, Samuels AL (2006) Composition of plant cuticular waxes. In: Riederer M, Müller C (ed) Annual plant reviews volume 23: Biology of the plant cuticle. Blackwell Publishing, Oxford, pp 145-181. https:/doi.org/10.1002/9780470988718.ch4

25. Jetter R, Schäffer S, Riederer M (2000) Leaf cuticular waxes are arranged in chemically and mechanically distinct layers: evidence from Prunus laurocerasus L. Plant Cell Environ 23(6):619-628. https://doi.org/10.1046/j.1365.3040.2000.00581.x

26. Karmakar A, Malik U, Barik A (2016) Effects of leaf epicuticular wax compounds from Solena amplexicaulis (Lam.) Gandhi on olfactory responses of a generalist insect herbivore. Allelopathy J 37: 253-272

27. Kim KH, Kabir E, Jahan SA (2017) Exposure to pesticides and the associated human health effects. Sci Total Env 575:525535. doi:10.1016/j.scitotenv.2016.09.009

28. Kim MS, Shim KB, Park SH, Kim KS (2009) Changes in cuticular waxes of developing leaves in sesame (Sesamum indicum L.). J Crop Sci Biotech 12 (3): 161-167. https://doi.org/10.1007/s12892-009-0119-3

29. Koschier EH, Kogel WJD, Visser JH (2000) Assessing the attractiveness of volatile plant compounds to western flower thrips Frankliniella occidentalis. J Chem Ecol 26: 2643-2655. https://doi.org/10.1023/A:1026470122171

30. Kumar M, Bera A, Gotyal BS, Naik MR, Kumar S (2014) Technologies for Sustainable Jute Fibre Production. Popular Kheti. 2(3):47-52

31. Kumar S, Ghorai AK, Kumar M, Nayak RK, Tripathi AN (2014) Cost effective technologies of jute production. Pop Kheti 2(2):12-15

32. Kumar S, Shamna A, Roy ML, Jha SK (2017) Impact of herbicide application on fibre yield of jute (Corchorus spp.) in West Bengal. Int J Sci Env Technol 6(2):1360-1366

33. Kumari S (2020) Trichomes size and structure in sunflower (Helianthus annuus L.) leaf under nitrogen deficiency. Int J Curr Microbiol App Sci 9(3): 2318-2322. https://doi.org/10.20546/ijcmas.2020.903.263

34. Li G, Ishikawa Y (2006) Leaf epicuticular wax chemicals of the Japanese knotweed Fallopia japonica as oviposition stimulants for Ostrinia latipennis. J Chem Ecol 32: 595-604. https://doi.org/10.1007/s1088 6-005-9022-7

35. Little CM, Chapman TW, Hillier NK (2019) Considerations for Insect Learning in Integrated Pest Management. J Insect Sci 19(4):1-14. https://doi.org/10.1093/jisesa/iez064

Page $13 / 21$ 
36. Lucas-Barbosa D, Sun P, Hakman A, Van Beek TA, Van Loon JJA, Dicke M (2016) Visual and odour cues: plant responses to pollination and herbivory affect the behaviour of flower visitors. Functional Ecol 30(3):431-441.

https://doi.org/10.1111/1365-2435.12509

37. Mahapatra BS, Mitra S, Ramasubramanian T, Sinha MK (2009) Research on jute (Corchorus olitorius and C. capsularis) and kenaf (Hibiscus cannabinus and H. sabdariffa): present status and future perspective. Ind J Agric Sci 79 (12):951-67

38. Malik U, Barik A (2015) Free fatty acids from the weed, Polygonum orientale leaves for attraction of the potential biocontrol agent, Galerucella placida (Coleoptera: Chrysomelidae). Biocontrol Sci Techn 25:593-607.

https://doi.org/10.1080/09583157.2014.1000264

39. Malik U, Mitra S, Barik A (2017) Attraction of the biocontrol agent, Galerucella placida Baly (Coleoptera: Chrysomelidae) to the leaf surface alkanes of the weed, Polygonum orientale L. Allelopathy J 40:103-116. https://doi.org/10.26651/2017-401070

40. Mathew LK (2016) Botanicals as biopesticides: a review. Int J Adv Res 4(3):1734-1739

41. Mazumdar SP, Kundu DK, Dey RK, Saha AR, Majumdar B, Sasmal S (2016) Effect of sulphur application on performance of fibre yield of different varieties of jute. Jaf News 14(1): 17.

42. McCallum EJ, Cunningham JP, Lücker J, Zalucki MP, De Voss JJ, Botella JR (2011) Increased plant volatile production affects oviposition, but not larval development, in the moth Helicoverpa armigera. The J Exp Biol 214:3672-3677

43. Mitra P, Das S, Barik A (2020) Leaf waxes from Lathyrus sativus: Short-range attractant and stimulant for nymph laying in a viviparous insect. Chemoecol 30:117-129. https://doi.org/10.1007/s00049-020-00303-7

44. Mitra P, Das S, Debnath R, Mobarak SH, Barik A (2021) Identification of Lathyrus sativus plant volatiles causing behavioral preference of Aphis craccivora. Pest Management Science 77 (1):285-299. https://doi.org /10.1002/ps.6018

45. Mitra P, Mobarak SH, Debnath R, Barik A (2019) The role of Lathyrus sativus flower surface wax in short-range attraction and stimulant for nymph laying by an adult viviparous aphid. Bull Entomol Res 110(2):231-241.

https://doi.org/10.1017/S0007485319000531

46. Mitra S, Sarkar N, Barik A (2017) Long-chain alkanes and fatty acids from Ludwigia octovalvis weed leaf surface waxes as shortrange attractant and ovipositional stimulant to Altica cyanea (Weber) (Coleoptera: Chrysomelidae). Bull Entomol Res 107(3): 391-400. https://doi.org/10.1017/s0007485316001012

47. Mobarak SH, Koner A, Mitra S, Mitra P, Barik A (2020a) The importance of leaf surface wax as short-range attractant and oviposition stimulant in a generalist Lepidoptera. J Appl Entomol 144(7):1-16. https://doi.org/10.1111/jen.12769

48. Mobarak SH, Roy N, Barik A (2020b) Two-sex life table and feeding dynamics of Spilosoma obliqua Walker (Lepidoptera: Arctiidae) on three green gram cultivars. Bull Entomol Res 110:219-230. https://doi:10.1017/S0007485319000452

49. Mohapatra MM, Gupta PK (2018) Evaluation of insecticides against Bihar Hairy Caterpillar, Spilosoma obliqua Walk. on black gram, Vigna mungo (Linn.). Int J Curr Microbiol App Sci 7(6):605-608. https://doi.org/10.20546/ijcmas.2018.706.069

50. Mukherjee A, Sarkar N, Barik A (2014) Long-chain free fatty acids from Momordica cochinchinensis leaves as attractants to its insect pest, Aulacophora foveicollis Lucas (Coleoptera: Chrysomelidae). J Asia-Pac Entomol 17(1):229-234.

https://doi.org/10.1016/j.aspen.2014.01.010

51. Mukherjee A, Sarkar N, Barik A (2015) Leaf surface n-alkanes of Momordica cochinchinensis Spreng as short-range attractants for its insect pest, Aulacophora foveicollis Lucas (Coleoptera: Chrysomelidae). Alleopathy Journal 36:109-122.

52. Müller C (2006) Plant-insect interactions on cuticular surfaces. Annu Plant Rev 23:398-422. https://doi.org/10.1002/9780470988718.ch13

53. Müller C, Hilker M (2001) Host finding and oviposition behavior in a chrysomelid specialist-the importance of host plant surface waxes. J Chem Ecol 27: 985-994. https://doi.org/10.1023/A:1010343205114

54. Müller C, Riederer M (2005) Plant surface properties in chemical ecology. J Chem Ecol 31: 2621-2651. https://doi.org/10.1007/s10886-005-7617-7

55. Naik RK, Karmakar PG (2016) Mechanization of jute cultivation. Agric Engin Today 40(2): 62-69

56. NIST (2008) Mass spectral database for NIST/EPA/NIH and mass spectral search program (Version 2.0f). Natl Inst Stand Technol, Gaithersburg, MD 208996

Page 14/21 
57. Omura H, Honda K, Hayashi N (1999) Chemical and chromatic bases for preferential visiting by the cabbage butterfly, Pieris rapae, to rape flowers. J Chem Ecol 25:1895-1906. https://doi.org/10.1023/A:1020990018111

58. Parr MJ, Tran BMD, Simmonds MSJ, Kite GC, Credland PF (1998) Influence of some fatty acids on oviposition by the bruchid beetle, Callosobruchus maculatus. J Chem Ecol 24:1577-1593. https://doi.org/10.1023/A:1020894410107

59. Parui A, Roy N (2016) Ecofriendly and sustainable management of Spilosoma obliqua Walker on sesame (Sesamum indicum L.) crops by new botanicals. J Ento Zoo Stud 4(6): 349-354

60. Phelan PL, Roelofs CJ, Youngman RR, Baker TC (1991) Characterization of chemicals mediating ovipositional host-plant finding by Amyelois transitella females. J Chem Ecol 17:599-613

61. Raguso RA, Willis MA (2005) Synergy between visual and olfactory cues in nectar feeding by wild hawkmoths, Manduca sexta. Animal Behav 69: 407-418. https://doi.org/10.1016/j.anbehav.2004.04.015

62. Rahman S, Khan MR (2012) Incidence of pests in jute (Corchorus olitorius L.) ecosystem and pest-weather relationships in West Bengal, India, Arch. Phytopath Plant Protect 45(5): 591-607

63. Rahman S, Khan MR (2006) Incidence of pests and avoidable yield loss in jute, Corchorus olitorius L. Ann Plant Protect Sci 14(2): 304-305

64. Renwick J, Chew FS (1994) Oviposition behavior in Lepidoptera. Annu Rev Entomol 39: 377-400. https://doi.org/10.1146/annurev.en.39.010194.002

65. Roy N (2015a) Host phytochemicals in regulation of nutritional ecology and population dynamics of Podontia quatuordecimpunctata L. (Coleoptera: Chrysomelidae). Int J Hort 5(4):1-11. https://doi:10.5376/ijh.2015.05.0004

66. Roy N (2015b) Life table and population parameters of Diacrisia casignetum Kollar (Lepidoptera: Arctiidae) on jute, Chorchorus capsularis (cv. Sonali; JRC-321), leaves. Int J Fauna Biol Stud 2: 23-29

67. Roy N (2017) Life table and nutritional ecology of Epilachna vigintioctopunctata Fab. (Coleoptera: Coccinellidae) on three host plants. Int J Hort 7(2):7-19. https://doi:10.5376/ijh.2017.07.0002

68. Roy N (2019a) Jute leaf physicochemical cues mediated behavioral responses of Diacrisia casignetum Kollar. Agric Res 8 : 287-296. https://doi.org/10.1007/s40003-018-0362-2

69. Roy N (2019b) Life table and economic threshold concept for ecologically sustainable management of Diacrisia casignetum Kollar (Lepidoptera: Arctiidae) on jute. Entomon 44(2):103-110. https://doi.org/10.33307/entomon.v44i.436

70. Roy N (2020) Population ecology and ETs based time series for climate smart pest management of Spilosoma obliqua Walker. Entomon 45(1): 15-30. https://doi.org/10.33307

71. Roy N (2021a) Population dynamics and economic thresholds based time series for smart pest management of sesame. Int J Trop Insect Sci pp 1-12. https://doi.org/10.1007/s42690-021-00437-3

72. Roy N (2021b) Synergism in host selection behaviour of three generalists towards leaf cuticular wax of sesame cultivars. Neot Entomol pp 1-16. https://doi.org/10.1007/s13744-021-00892-0

73. Roy N Barik A (2014) Long-chain fatty acids: semiochemicals for host location by the insect pest, Diacrisia casignetum.JKansas Entomol Society 87: 22-36. https://doi.org/10.2317/JKES130521.1

74. Roy N, Barik A (2012a) The impact of variation in foliar constituents of sunflower on development and reproduction of Diacrisia casignetum Kollar (Lepidoptera: Arctiidae). Psyche, vol. 2012: 9 pages. https://doi:10.1155/2012/812091

75. Roy N, Barik A (2012b) Alkanes used for host recognition by the arctiid moth, Diacrisia casignetum Kollar. J Entomol Res 36: 345-350

76. Roy N, Barik A (2013) Influence of four host plants on feeding, growth and reproduction of Diacrisia casignetum (Lepidoptera: Arctiidae). Entomol Sci 16(1): 112-118. https://doi.org/10.1111/j.1479-8298.2012.00546.x

77. Roy N, Laskar S, and Barik A (2012a) The attractiveness of odorous esterified fatty acids to the potential biocontrol agent, Altica cyanea. J Asia Pacific Entomol15: 277-282. https://doi.org/10.1016/j.aspen.2012.03.001

78. Roy N, Laskar S, Barik A (2012b) Determination of $n$-alkane profile through developmental state of sunflower leaves. The South Pacific J Nat Appl Sci 30: 72-76. https://doi.org/10.1071/sp12008 
79. Sarkar N, Mukherjee A, Barik A (2013a) Long-chain alkanes: allelochemicals for host location by the insect pest, Epilachna dodecastigma (Coleoptera: Coccinellidae). Appl Entomol Zool 48:171-179. https://doi.org/10.1007/s13355-013-0168-4

80. Sarkar N, Mukherjee A, Barik A (2013b) Olfactory responses of Epilachna dodecastigma (Coleoptera: Coccinellidae) to longchain fatty acids from Momordica charantia leaves. Arthropod-Plant Interact 7:339-348. https://doi.org/10.1007/s11829013-9249-0

81. Sarkar S, Majumdar B (2013) Feasibility of growing intercrops with jute (Corchorus olitorius L.) grown for seed production in West Bengal. Ind J Crop Weed 9(1): 36-37

82. Sarkar S, Majumdar B (2016) Present status of jute production and technological and social interventions needed for making jute agriculture sustainable and remunerative in West Bengal. Ind J Natural Fibres 3(1): 23-36

83. Sarkar SK, Gawande SP (2016) Diseases of jute and allied fibre crops and their management. J Mycopath Res 54(3): 32133

84. Schoonhoven LM, Van Loon JJA, Dicke M (2005) Insect-plant Biology. Oxford University Press, Oxford, U.K.

85. Silva MMA, Santos DYAC, Melo-de-Pinna GFA, Câmarac TJR, Oliveira AFM (2017) Chemical composition and ultrastructure of the foliar cuticular wax of two Brazilian cultivars of castor bean (Ricinus communis L.). Ind Crops Prod 95: 558-563. http://dx.doi.org/10.1016/j.indcrop.2016.11.010

86. Singh I, Singh G (1992) Assessment of foliage loss caused by different larval instars of Bihar hairy caterpillar, Spilosoma obliqua (Walker) on sunflower. J Insect Sci 6 (2):185-186

87. Singh R, Koul O, Rup PJ, Jindal J (2011) Oviposition and feeding behavior of the maize borer, Chilo partellus, in response to eight essential oil allelochemicals. Entomol Exp Appl 138(1):55-64. https://doi.org/10.1111/j.1570-7458.2010.01071.x

88. Singh YR, Varatharajan R (1999) Host range of Bihar hairy caterpillar, Spilosoma obliqua (Walker) (Arctiidae: Lepidoptera). Hexapoda 11 (2):65-74

89. Turlings TCJ, Davison AC, Tamò C (2004) A six-arm olfactometer permitting simultaneous observation of insect attraction and odour trapping. Physiol Entomol 29(1): 1-11. https://doi.org/10.1111/j.1365-3032.2004.0362.x

90. Udayagiri S, Mason CE (1997) Epicuticular wax chemicals in Zea mays influence oviposition in Ostrinia nubilalis. J Chem Ecol 23: 1675-1687. https://doi.org/10.1023/B:JOEC.0000006443.72203.f7

91. Van Loon JJA, Blaakmeer A, Griepink FC, Van Beek TA, Schoonhoven LM, De Groot AE (1992) Leaf surface compound from Brassica oleracea (Cruciferae) induces oviposition by Pieris brassicae (Lepidoptera: Pieridae). Chemoecol 3: 39-44. https://doi.org/10.1007/BF01261455

92. Varatharajan R, Singh SA, Keisa TJ, Singh OD, Selvasundaram R (1998) Life table of Spilosoma obliqua (Lepidoptera: Arctiidae) on sunflower. Insect Sci Appl 18: 383-385. https://doi.org/10.1017/s1742758400018634

93. Wadhera D, Capaldi-Phillips ED (2014) A review of visual cues associated with food on food acceptance and consumption. Eat Behav 15(1): 132-43. https://doi.org/10.1016/j.eatbeh.2013.11.003

94. Wang Y, Wang J, Chai G, Li C, Hu Y, Chen X, Wang Z (2015) Developmental changes in composition and morphology of cuticular waxes on leaves and spikes of glossy and glaucous Wheat (Triticum aestivum L.). PLoS ONE 10: e0141239. https://doi.org/10.1371/journal.pone.0141239

95. Zar JH (1999) Biostatistical Analysis. Prentice Hall, Upper Saddle River, New Jersey, USA, pp 663

\section{Tables}

Table 1 Composition of $n$-alkanes $\left(\mu\right.$ leaf $^{-1}$ ) in plant surface waxes (Mean $\pm S E, n=3$ ) of three selected host (white jute, Corchorus capsularis, tossa jute, C. olitorius and mesta jute, Hibiscus cannabinus [Malvaceae]) plants determined during their growing season in 2020-2021. 


\begin{tabular}{|c|c|c|c|c|c|}
\hline Alkanes ( $\mu \mathrm{g} / \mathrm{leaf})$ & White Jute & Tossa Jute & Mesta Jute & $F_{2,6}$ & $P$ \\
\hline $\mathrm{n}$-Tetradecane (n-C14) & $0.785 \pm 0.052^{\mathrm{a}}$ & $0.325 \pm 0.016^{b}$ & $0.116 \pm 0.012^{c}$ & 114.480 & $<0.001$ \\
\hline n-Pentadecane (n-C15) & $8.662 \pm 0.572^{\mathrm{a}}$ & $2.029 \pm 0.098^{b}$ & $1.266 \pm 0.126^{c}$ & 140.608 & $<0.001$ \\
\hline n-Hexadecane (n-C16) & $27.254 \pm 1.801^{a}$ & $11.099 \pm 0.536^{b}$ & $3.203 \pm 0.319^{c}$ & 124.166 & $<0.001$ \\
\hline n-Octadecane (n-C18) & $40.741 \pm 2.692^{\mathrm{a}}$ & $17.179 \pm 0.829^{b}$ & $5.305 \pm 0.528^{c}$ & 118.833 & $<0.001$ \\
\hline n-Eicosane (n-C20) & $35.993 \pm 2.378^{a}$ & $16.211 \pm 0.783^{b}$ & $4.872 \pm 0.485^{c}$ & 114.435 & $<0.001$ \\
\hline n-Docosane (n-C22) & $29.520 \pm 1.950^{\mathrm{a}}$ & $13.037 \pm 0.629^{b}$ & $3.937 \pm 0.392^{c}$ & 115.874 & $<0.001$ \\
\hline n-Tricosane (n-C23) & $2.162 \pm 0.143^{a}$ & $1.166 \pm 0.056^{b}$ & $0.131 \pm 0.013^{\mathrm{c}}$ & 130.268 & $<0.001$ \\
\hline n-Tetracosane (n-C24) & $7.696 \pm 0.509^{a}$ & $1.827 \pm 0.088^{b}$ & $0.220 \pm 0.022^{c}$ & 174.120 & $<0.001$ \\
\hline n-Pentacosane (n-C25) & $23.262 \pm 1.537^{a}$ & $10.072 \pm 0.486^{b}$ & $3.287 \pm 0.327^{c}$ & 114.393 & $<0.001$ \\
\hline n-Hexacosane (n-C26) Branch & $4.675 \pm 0.309^{a}$ & - & - & 229.065 & $<0.001$ \\
\hline n-Hexacosane (n-C26) & $7.110 \pm 0.470^{a}$ & $2.799 \pm 0.135^{b}$ & $0.581 \pm 0.058^{\mathrm{c}}$ & 136.477 & $<0.001$ \\
\hline n-Heptacosane (n-C27) & $18.384 \pm 1.215^{\mathrm{a}}$ & $7.833 \pm 0.378^{b}$ & $2.469 \pm 0.246^{c}$ & 117.156 & $<0.001$ \\
\hline n-Octacosane (n-C28) Branch & $1.811 \pm 0.120^{\mathrm{a}}$ & - & - & 229.065 & $<0.001$ \\
\hline n-Octacosane (n-C28) & $9.481 \pm 0.626^{a}$ & $11.322 \pm 0.547^{b}$ & $4.495 \pm 0.447^{c}$ & 41.996 & $<0.001$ \\
\hline n-Nonacosane (n-C29) & $13.426 \pm 0.887^{a}$ & $7.250 \pm 0.350^{\mathrm{b}}$ & $2.418 \pm 0.241^{\mathrm{c}}$ & 94.419 & $<0.001$ \\
\hline n-Triacontane (n-C30) Branch & $3.256 \pm 0.215^{a}$ & - & - & 229.065 & $<0.001$ \\
\hline n-Triacontane (n-C30) & $14.032 \pm 0.927^{a}$ & $25.373 \pm 1.225^{b}$ & $11.493 \pm 1.144^{\mathrm{c}}$ & 44.670 & $<0.001$ \\
\hline $\mathrm{n}$-Hentriacontane (n-C31) & $9.441 \pm 0.624^{\mathrm{a}}$ & $7.359 \pm 0.355^{b}$ & $3.046 \pm 0.303^{c}$ & 52.565 & $<0.001$ \\
\hline n-Dotriacontane (n-C32) Branch & $9.438 \pm 0.624^{a}$ & $3.284 \pm 0.159^{b}$ & $1.649 \pm 0.164^{c}$ & 114.770 & $<0.001$ \\
\hline n-Dotriacontane (n-C32) & $24.724 \pm 1.634^{\mathrm{a}}$ & $82.465 \pm 3.981^{b}$ & $40.862 \pm 4.067^{c}$ & 75.952 & $<0.001$ \\
\hline n-Tritriacontane (n-C33) & $7.832 \pm 0.518^{a}$ & $15.840 \pm 0.765^{b}$ & $7.719 \pm 0.768^{a}$ & 45.087 & $<0.001$ \\
\hline n-Tetratriacontane (n-C34) Branch & $12.191 \pm 0.805^{a}$ & $11.741 \pm 0.567^{b}$ & $6.616 \pm 0.658^{c}$ & 20.501 & 0.002 \\
\hline n-Tetratriacontane (n-C34) & $33.082 \pm 2.186^{\mathrm{a}}$ & $144.397 \pm 6.971^{\mathrm{b}}$ & $77.921 \pm 7.756^{c}$ & 82.899 & $<0.001$ \\
\hline n-Pentatriacontane (n-C35) Branch & - & $1.585 \pm 0.077^{a}$ & $0.801 \pm 0.080^{b}$ & 154.329 & $<0.001$ \\
\hline n-Pentatriacontane (n-C35) & $6.924 \pm 0.457^{\mathrm{a}}$ & $17.402 \pm 0.840^{b}$ & $9.291 \pm 0.925^{\mathrm{c}}$ & 51.183 & $<0.001$ \\
\hline n-Hexatriacontane (n-C36) Branch & - & $5.796 \pm 0.280^{a}$ & $3.405 \pm 0.339^{b}$ & 131.776 & $<0.001$ \\
\hline n-Hexatriacontane (n-C36) & $8.841 \pm 0.584^{a}$ & $34.199 \pm 1.651^{\mathrm{b}}$ & $19.254 \pm 1.916^{c}$ & 72.320 & $<0.001$ \\
\hline
\end{tabular}

Note: Within rows and columns means followed by same letters (lower and upper case, respectively) are not significantly different $(P \geq 0.05)$ by Tukey's HSD test. 
Table 2 Composition of free fatty acids (FFAs) $\left(\mu\right.$ leaf $^{-1}$ ) in plant surface waxes (Mean $\pm S E, n=3$ ) of three selected host (white jute, Corchorus capsularis, tossa jute, C. olitorius and mesta jute, Hibiscus cannabinus [Malvaceae]) plants determined during their growing season in 2020-2021.

\begin{tabular}{llllll} 
Free Fatty Acids $(\mu \mathrm{g} / \mathrm{leaf})$ & White Jute & Tossa Jute & Mesta Jute & $\boldsymbol{F}_{2,6}$ & $\boldsymbol{P}$ \\
\hline Dodecanoic acid (C12:0) & $2.679 \pm 0.126^{\mathrm{a}}$ & $0.267 \pm 0.006^{\mathrm{b}}$ & $1.200 \pm 0.100^{\mathrm{c}}$ & 171.210 & $<0.001$ \\
\hline Tridecanoic acid (C13:0) & $1.440 \pm 0.068^{\mathrm{a}}$ & $0.777 \pm 0.018^{\mathrm{b}}$ & $2.868 \pm 0.240^{\mathrm{c}}$ & 54.999 & $<0.001$ \\
\hline Tetradecanoic acid (C14:0) & $0.952 \pm 0.045^{\mathrm{a}}$ & $2.238 \pm 0.051^{\mathrm{b}}$ & $5.532 \pm 0.462^{\mathrm{c}}$ & 76.726 & $<0.001$ \\
\hline Pentadecenoin acid (C15:0) & $1.481 \pm 0.070^{\mathrm{a}}$ & $1.991 \pm 0.046^{\mathrm{b}}$ & $3.044 \pm 0.254^{\mathrm{c}}$ & 26.628 & 0.001 \\
\hline Trihexadecanoin acid (C16:1) & $24.846 \pm 1.167^{\mathrm{a}}$ & $37.034 \pm 0.848^{\mathrm{b}}$ & $21.777 \pm 1.819^{\mathrm{c}}$ & 36.242 & $<0.001$ \\
\hline Hexadecanoic acid (C16:0) & $14.801 \pm 0.695^{\mathrm{a}}$ & $5.226 \pm 0.120^{\mathrm{b}}$ & $4.273 \pm 0.357^{\mathrm{c}}$ & 162.635 & $<0.001$ \\
\hline Heptadecanoic acid (C17:0) & $0.866 \pm 0.041^{\mathrm{a}}$ & $0.263 \pm 0.006^{\mathrm{b}}$ & $1.551 \pm 0.130^{\mathrm{c}}$ & 67.443 & $<0.001$ \\
\hline Trioctadecadienoin acid (C18:2) & $0.268 \pm 0.013^{\mathrm{a}}$ & - & - & 452.966 & $<0.001$ \\
\hline Trioctadecenoin acid (C18:1) & $0.474 \pm 0.022^{\mathrm{a}}$ & $1.581 \pm 0.036^{\mathrm{b}}$ & $0.556 \pm 0.046^{\mathrm{a}}$ & 287.977 & $<0.001$ \\
\hline Octadecanoic acid (C18:0) & $1.628 \pm 0.076^{\mathrm{a}}$ & $3.293 \pm 0.075^{\mathrm{b}}$ & $1.463 \pm 0.122^{\mathrm{a}}$ & 116.105 & $<0.001$ \\
\hline Nonadecanoic acid (C19:0) & $3.425 \pm 0.161^{\mathrm{a}}$ & $3.854 \pm 0.088^{\mathrm{a}}$ & $6.966 \pm 0.582^{\mathrm{b}}$ & 30.100 & 0.001 \\
\hline Eicosanoic acid (C20:0) & $3.938 \pm 0.185^{\mathrm{a}}$ & $2.810 \pm 0.064^{\mathrm{b}}$ & $2.576 \pm 0.215^{\mathrm{b}}$ & 18.793 & 0.003 \\
\hline Heneicosanoic acid (C21:0) & $2.376 \pm 0.112^{\mathrm{a}}$ & $2.485 \pm 0.057^{\mathrm{b}}$ & $0.468 \pm 0.039^{\mathrm{b}}$ & 223.992 & $<0.001$ \\
\hline Docosanoic acid (C22:0) & $16.488 \pm 0.775^{\mathrm{a}}$ & $13.888 \pm 0.318^{\mathrm{b}}$ & $3.161 \pm 0.264^{\mathrm{c}}$ & 194.174 & $<0.001$
\end{tabular}

Note: Within rows and columns means followed by same letters (lower and upper case, respectively) are not significantly different $(P \geq 0.05)$ by Tukey's HSD test.

Table 3 Adult olfactory attraction (Mean $\pm S E, n=72$ ) of a generalist jute pest (Spilosoma obliqua Walker; Arctiidae) to plant surface wax chemicals (n-alkanes and FFAs in leaf equivalent amount [ $\left.\mu \mathrm{g} \mathrm{leaf}^{-1}\right]$ ) of three selected host (white jute, Corchorus capsularis, tossa jute, C. olitorius and mesta jute, Hibiscus cannabinus [Malvaceae]) plants under specified bioassay conditions. 


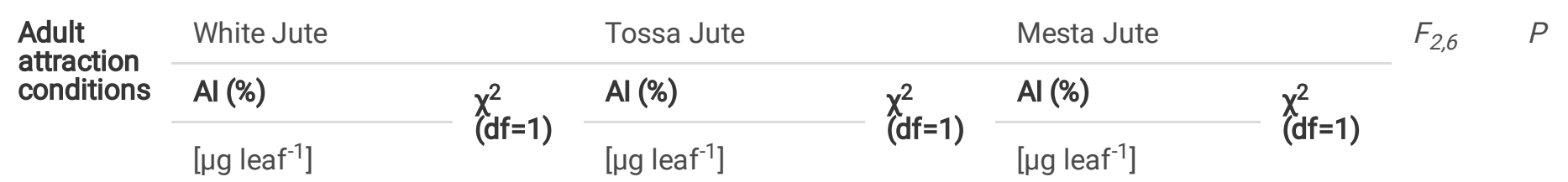

Alkanes treated filter paper vs. solvent:

\begin{tabular}{|c|c|c|c|c|c|c|c|c|}
\hline \multirow{2}{*}{$\begin{array}{l}\text { Total } \\
\text { natural n- } \\
\text { alkanes }\end{array}$} & $13.426 \pm 2.018^{a}$ & \multirow[t]{2}{*}{2.236} & $10.648 \pm 2.018^{b}$ & \multirow[t]{2}{*}{1.505} & $7.870 \pm 2.018^{c}$ & \multirow[t]{2}{*}{0.905} & \multirow[t]{2}{*}{1.895} & \multirow[t]{2}{*}{0.230} \\
\hline & {$[360.628 \pm 23.779]$} & & {$[451.570 \pm 21.825]$} & & {$[214.379 \pm 21.344]$} & & & \\
\hline \multirow{2}{*}{$\begin{array}{l}\text { Synthetic } \\
4 \mathrm{n} \text { - } \\
\text { alkanes } \\
\text { mixture }\end{array}$} & $18.982 \pm 2.370^{a}$ & \multirow[t]{2}{*}{3.571} & $14.815 \pm 2.137^{b}$ & \multirow[t]{2}{*}{2.330} & $10.648 \pm 2.095^{c}$ & \multirow[t]{2}{*}{1.316} & \multirow[t]{2}{*}{4.263} & \multirow[t]{2}{*}{0.070} \\
\hline & [133.508 \pm 3.727$]$ & & [57.526 1.836$]$ & & 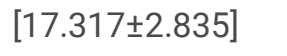 & & & \\
\hline
\end{tabular}

Free fatty acids (FFAs) treated filter paper vs. solvent:

\begin{tabular}{|c|c|c|c|c|c|c|c|c|}
\hline \multirow{2}{*}{$\begin{array}{l}\text { Total } \\
\text { natural } \\
\text { FFAs }\end{array}$} & $32.870 \pm 2.106^{a}$ & \multirow[t]{2}{*}{8.147} & $30.093 \pm 2.092^{\mathrm{a}}$ & \multirow[t]{2}{*}{7.039} & $25.926 \pm 2.104^{b}$ & \multirow[t]{2}{*}{5.480} & \multirow[t]{2}{*}{3.00} & \multirow[t]{2}{*}{0.125} \\
\hline & 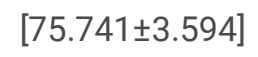 & & {$[75.766 \pm 1.763]$} & & {$[55.500 \pm 4.660]$} & & & \\
\hline \multirow{2}{*}{$\begin{array}{l}\text { Synthetic } \\
5 \text { FFAs } \\
\text { mixture }\end{array}$} & $45.370 \pm 2.148^{a}$ & \multirow[t]{2}{*}{20.542} & $42.593 \pm 2.076^{b}$ & \multirow[t]{2}{*}{18.831} & $38.426 \pm 2.073^{c}$ & \multirow[t]{2}{*}{16.311} & \multirow[t]{2}{*}{3.00} & \multirow[t]{2}{*}{0.125} \\
\hline & {$[61.701 \pm 2.713]$} & & {$[62.251 \pm 1.603]$} & & {$[33.250 \pm 2.059]$} & & & \\
\hline
\end{tabular}

Combined mixture treated filter paper vs. solvent:

\begin{tabular}{|c|c|c|c|c|c|c|c|c|}
\hline \multirow{2}{*}{$\begin{array}{l}\text { Total } \\
\text { natural } \\
\text { wax }\end{array}$} & $57.870 \pm 2.117^{a}$ & \multirow[t]{2}{*}{30.474} & $53.704 \pm 2.038^{b}$ & \multirow[t]{2}{*}{27.704} & $49.537 \pm 2.116^{c}$ & \multirow[t]{2}{*}{24.962} & \multirow[t]{2}{*}{4.263} & \multirow[t]{2}{*}{0.070} \\
\hline & {$[1064.175 \pm 83.481]$} & & [1187.578 \pm 70.683$]$ & & {$[728.029 \pm 34.226]$} & & & \\
\hline \multirow{2}{*}{$\begin{array}{l}\text { Synthetic } \\
\text { wax }(4 \mathrm{n}- \\
\text { alknes+5 } \\
\text { FFAs) } \\
\text { mixture }\end{array}$} & $68.519 \pm 1.225^{a}$ & \multirow[t]{2}{*}{38.853} & $66.667 \pm 1.389^{a}$ & \multirow[t]{2}{*}{37.579} & $62.963 \pm 2.816^{b}$ & \multirow[t]{2}{*}{35.046} & \multirow[t]{2}{*}{2.113} & \multirow[t]{2}{*}{0.202} \\
\hline & {$[195.209 \pm 2.950]$} & & {$[119.777 \pm 1.857]$} & & {$[50.567 \pm 3.508]$} & & & \\
\hline
\end{tabular}

\section{Combined synthetic mixture (4 n-alknes+5 FFAs) treated leaf vs. solvent:}

\begin{tabular}{|c|c|c|c|c|c|c|c|c|}
\hline \multirow[t]{2}{*}{ Intact leaf } & $83.796 \pm 1.669^{a}$ & \multirow[t]{2}{*}{52.262} & $77.315 \pm 4.560^{c}$ & \multirow[t]{2}{*}{47.687} & $73.148 \pm 2.078^{b}$ & \multirow[t]{2}{*}{43.353} & \multirow[t]{2}{*}{3.124} & \multirow[t]{2}{*}{0.118} \\
\hline & {$[1259.384 \pm 72.213]$} & & [1307.355士66.820] & & [778.596 \pm 29.359$]$ & & & \\
\hline \multirow{2}{*}{$\begin{array}{l}\text { De-waxed } \\
\text { leaf }\end{array}$} & $70.370 \pm 2.016^{a}$ & \multirow[t]{2}{*}{38.909} & $64.815 \pm 2.085^{\mathrm{b}}$ & \multirow[t]{2}{*}{35.139} & $62.037 \pm 2.092^{b}$ & \multirow[t]{2}{*}{33.266} & \multirow[t]{2}{*}{4.421} & \multirow[t]{2}{*}{0.066} \\
\hline & {$[195.209 \pm 2.950]$} & & {$[119.777 \pm 1.857]$} & & {$[50.567 \pm 3.508]$} & & & \\
\hline
\end{tabular}

Note: Within rows means followed by same letters are not significantly different $(P \geq 0.05)$ by Tukey's HSD test. Al=Attraction index.

Table 4 Oviposition preference (Mean $\pm S E, n=72$ ) of a generalist jute pest (Spilosoma obliqua Walker; Arctiidae) to plant surface wax chemicals (n-alkanes and FFAs in leaf equivalent amount $\left[\mu\right.$ leaf $\left.^{-1}\right]$ ) of three selected host (white jute, Corchorus capsularis, tossa jute, C. olitorius and mesta jute, Hibiscus cannabinus [Malvaceae]) plants under specified bioassay conditions. 


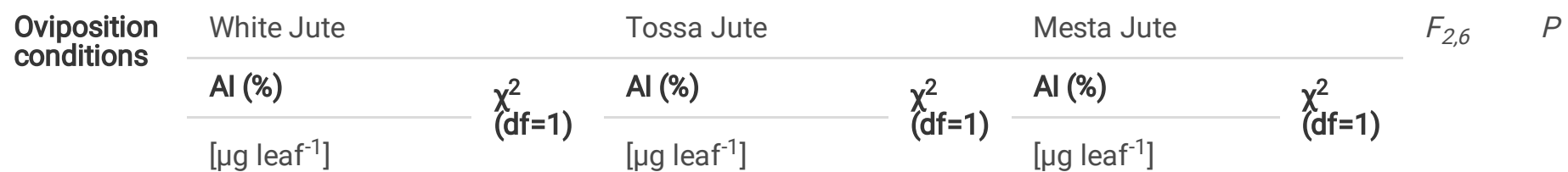

Alkanes treated filter paper vs. solvent:

\begin{tabular}{|c|c|c|c|c|c|c|c|c|}
\hline \multirow{2}{*}{$\begin{array}{l}\text { Total } \\
\text { natural n- } \\
\text { alkanes }\end{array}$} & $34.199 \pm 9.985^{a}$ & \multirow[t]{2}{*}{1.234} & $26.732 \pm 2.347^{b}$ & \multirow[t]{2}{*}{0.744} & $22.540 \pm 5.643^{c}$ & \multirow[t]{2}{*}{0.448} & \multirow[t]{2}{*}{0.807} & \multirow[t]{2}{*}{0.489} \\
\hline & {$[360.628 \pm 23.779]$} & & {$[451.570 \pm 21.825]$} & & {$[214.379 \pm 21.344]$} & & & \\
\hline \multirow{2}{*}{$\begin{array}{l}\text { Synthetic } 4 \\
\text { n-alkanes } \\
\text { mixture }\end{array}$} & $41.667 \pm 8.333^{a}$ & \multirow[t]{2}{*}{1.833} & $32.778 \pm 4.339^{b}$ & \multirow[t]{2}{*}{0.922} & $37.771 \pm 6.429^{c}$ & \multirow[t]{2}{*}{1.353} & \multirow[t]{2}{*}{1.561} & \multirow[t]{2}{*}{0.285} \\
\hline & [133.508ะ3.727] & & {$[57.526 \pm 1.836]$} & & {$[17.317 \pm 2.835]$} & & & \\
\hline
\end{tabular}

Free fatty acids (FFAs) treated filter paper vs. solvent:

\begin{tabular}{|c|c|c|c|c|c|c|c|c|}
\hline \multirow{2}{*}{$\begin{array}{l}\text { Total } \\
\text { natural } \\
\text { FFAs }\end{array}$} & $36.793 \pm 6.873^{\mathrm{a}}$ & \multirow[t]{2}{*}{2.273} & $26.111 \pm 3.889^{b}$ & \multirow[t]{2}{*}{0.748} & $21.746 \pm 3.546^{c}$ & \multirow[t]{2}{*}{0.625} & \multirow[t]{2}{*}{1.273} & \multirow[t]{2}{*}{0.346} \\
\hline & {$[75.741 \pm 3.594]$} & & {$[75.766 \pm 1.763]$} & & {$[55.500 \pm 4.660]$} & & & \\
\hline \multirow{2}{*}{$\begin{array}{l}\text { Synthetic } 5 \\
\text { FFAs } \\
\text { mixture }\end{array}$} & $37.374 \pm 8.694^{\mathrm{a}}$ & \multirow[t]{2}{*}{1.980} & $49.801 \pm 4.925^{b}$ & \multirow[t]{2}{*}{2.716} & $23.148 \pm 6.481^{c}$ & \multirow[t]{2}{*}{0.648} & \multirow[t]{2}{*}{7.034} & \multirow[t]{2}{*}{0.027} \\
\hline & {$[61.701 \pm 2.713]$} & & {$[62.251 \pm 1.603]$} & & [33.250 \pm 2.059$]$ & & & \\
\hline
\end{tabular}

Combined mixture treated filter paper vs. solvent:

\begin{tabular}{|c|c|c|c|c|c|c|c|c|}
\hline \multirow{2}{*}{$\begin{array}{l}\text { Total } \\
\text { natural wax }\end{array}$} & $42.424 \pm 7.576^{\mathrm{a}}$ & \multirow[t]{2}{*}{2.606} & $38.730 \pm 2.822^{b}$ & \multirow[t]{2}{*}{1.835} & $34.286 \pm 7.190^{c}$ & \multirow[t]{2}{*}{1.524} & \multirow[t]{2}{*}{0.426} & \multirow[t]{2}{*}{0.672} \\
\hline & [1064.175 \pm 83.481$]$ & & [1187.578 \pm 70.683$]$ & & {$[728.029 \pm 34.226]$} & & & \\
\hline \multirow{2}{*}{$\begin{array}{l}\text { Synthetic } \\
\text { wax }(4 \mathrm{n}- \\
\text { alknes+5 } \\
\text { FFAs) } \\
\text { mixture }\end{array}$} & $63.981 \pm 5.250^{\mathrm{a}}$ & \multirow[t]{2}{*}{6.304} & $62.594 \pm 4.565^{a}$ & \multirow[t]{2}{*}{5.706} & $57.879 \pm 4.077^{b}$ & \multirow[t]{2}{*}{4.285} & \multirow[t]{2}{*}{0.472} & \multirow[t]{2}{*}{0.645} \\
\hline & [195.209 \pm 2.950$]$ & & [119.777士1.857] & & {$[50.567 \pm 3.508]$} & & & \\
\hline
\end{tabular}

\section{Combined synthetic mixture ( 4 n-alknes+5 FFAs) treated leaf vs. solvent:}

\begin{tabular}{|c|c|c|c|c|c|c|c|c|}
\hline \multirow[t]{2}{*}{ Intact leaf } & $80.278 \pm 4.092^{\mathrm{a}}$ & \multirow[t]{2}{*}{11.039} & $78.307 \pm 4.132^{\mathrm{a}}$ & \multirow[t]{2}{*}{9.439} & $69.167 \pm 3.632^{b}$ & \multirow[t]{2}{*}{8.350} & \multirow[t]{2}{*}{2.243} & \multirow[t]{2}{*}{0.187} \\
\hline & [1259.384 \pm 72.213$]$ & & [1307.355₫66.820] & & [778.596 29.359$]$ & & & \\
\hline \multirow{2}{*}{$\begin{array}{l}\text { De-waxed } \\
\text { leaf }\end{array}$} & $66.299 \pm 4.793^{a}$ & \multirow[t]{2}{*}{7.178} & $65.079 \pm 4.201^{a}$ & \multirow[t]{2}{*}{6.571} & $62.594 \pm 4.564^{\mathrm{b}}$ & \multirow[t]{2}{*}{5.706} & \multirow[t]{2}{*}{0.174} & \multirow[t]{2}{*}{0.844} \\
\hline & 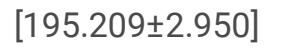 & & {$[119.777 \pm 1.857]$} & & {$[50.567 \pm 3.508]$} & & & \\
\hline
\end{tabular}

Note: Within rows and columns means followed by same letters (lower and upper case, respectively) are not significantly different $(P \geq 0.05)$ by Tukey's HSD test. OPI=Oviposition preference index (gravid female).

Table 5 Feeding preference (Mean $\pm S E, n=72$ ) of the $5^{\text {th }}$ instar larvae of a generalist jute pest (Spilosoma obliqua Walker; Arctiidae) to plant surface wax chemicals ( $n$-alkanes and FFAs in leaf equivalent amount [ $\mu$ leaf $\left.^{-1}\right]$ ) of three selected host (white jute, Corchorus capsularis, tossa jute, C. olitorius and mesta jute, Hibiscus cannabinus [Malvaceae]) plants under specified bioassay conditions. 


\begin{tabular}{|c|c|c|c|c|c|c|}
\hline Larval & White Jute & & Tossa Jute & & Mesta Jut & \\
\hline conditions & $\mathrm{FI}(\%)$ & & $\mathrm{FI}(\%)$ & & FI (\%) & $x^{2}$ \\
\hline & {$\left[\mu\right.$ leaf $\left.^{-1}\right]$} & & {$\left[\mu\right.$ leaf $\left.^{-1}\right]$} & & [ $\mu$ g leaf $\left.{ }^{-1}\right]$ & \\
\hline
\end{tabular}

Alkanes treated intact leaf vs. solvent:

\begin{tabular}{|c|c|c|c|c|c|c|c|c|}
\hline \multirow{2}{*}{$\begin{array}{l}\text { Total } \\
\text { natural n- } \\
\text { alkanes }\end{array}$} & $33.465 \pm 0.808^{a}$ & \multirow[t]{2}{*}{3.153} & $31.877 \pm 2.060^{\mathrm{b}}$ & \multirow[t]{2}{*}{2.614} & $32.488 \pm 1.494^{\mathrm{ab}}$ & \multirow[t]{2}{*}{2.808} & \multirow[t]{2}{*}{0.270} & \multirow[t]{2}{*}{0.772} \\
\hline & {$[1424.803 \pm 19.490]$} & & 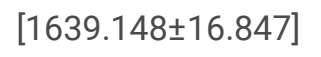 & & [942.408 \pm 18.280$]$ & & & \\
\hline \multirow{2}{*}{$\begin{array}{l}\text { Synthetic } 4 \\
\text { n-alkanes } \\
\text { mixture }\end{array}$} & $36.573 \pm 2.938^{a}$ & \multirow[t]{2}{*}{2.792} & $35.063 \pm 1.655^{a}$ & \multirow[t]{2}{*}{2.317} & $35.779 \pm 2.220^{a}$ & \multirow[t]{2}{*}{2.530} & \multirow[t]{2}{*}{0.105} & \multirow[t]{2}{*}{0.902} \\
\hline & 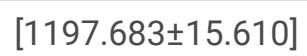 & & [1245.104₫13.503] & & [745.346士12.610] & & & \\
\hline
\end{tabular}

Free fatty acids (FFAs) treated intact leaf vs. solvent:

\begin{tabular}{|c|c|c|c|c|c|c|c|c|}
\hline \multirow{2}{*}{$\begin{array}{l}\text { Total } \\
\text { natural } \\
\text { FFAs }\end{array}$} & $37.307 \pm 3.645^{a}$ & \multirow[t]{2}{*}{3.170} & $35.937 \pm 2.353^{b}$ & \multirow[t]{2}{*}{2.670} & $36.322 \pm 2.704^{\mathrm{ab}}$ & \multirow[t]{2}{*}{2.801} & \multirow[t]{2}{*}{0.057} & \multirow[t]{2}{*}{0.945} \\
\hline & 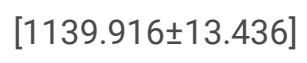 & & {$[1263.344 \pm 11.763]$} & & {$[783.529 \pm 14.507]$} & & & \\
\hline \multirow{2}{*}{$\begin{array}{l}\text { Synthetic } 5 \\
\text { FFAs } \\
\text { mixture }\end{array}$} & $37.550 \pm 3.863^{a}$ & \multirow[t]{2}{*}{2.713} & $36.382 \pm 2.773^{a}$ & \multirow[t]{2}{*}{2.343} & $36.715 \pm 3.075^{a}$ & \multirow[t]{2}{*}{2.443} & \multirow[t]{2}{*}{0.034} & \multirow[t]{2}{*}{0.967} \\
\hline & {$[1125.876 \pm 12.713]$} & & 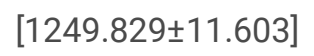 & & {$[761.279 \pm 12.106]$} & & & \\
\hline
\end{tabular}

Combined synthetic mixture ( 4 n-alknes +5 FFAs) treated leaf vs. solvent:

\begin{tabular}{|c|c|c|c|c|c|c|c|c|}
\hline \multirow[t]{2}{*}{ Intact leaf } & $38.854 \pm 5.163^{a}$ & \multirow[t]{2}{*}{3.537} & $36.452 \pm 2.827^{b}$ & \multirow[t]{2}{*}{2.605} & $37.952 \pm 4.276^{\mathrm{ab}}$ & \multirow[t]{2}{*}{3.149} & \multirow[t]{2}{*}{0.084} & \multirow[t]{2}{*}{0.921} \\
\hline & [1259.384 \pm 72.213$]$ & & 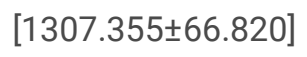 & & [778.596 \pm 29.359$]$ & & & \\
\hline \multirow{2}{*}{$\begin{array}{l}\text { De-waxed } \\
\text { leaf }\end{array}$} & $38.930 \pm 5.216^{a}$ & \multirow[t]{2}{*}{3.173} & $36.549 \pm 2.925^{b}$ & \multirow[t]{2}{*}{2.344} & $36.992 \pm 3.332^{b}$ & \multirow[t]{2}{*}{2.477} & \multirow[t]{2}{*}{0.103} & \multirow[t]{2}{*}{0.904} \\
\hline & {$[195.209 \pm 2.950]$} & & [119.777士1.857] & & {$[50.567 \pm 3.508]$} & & & \\
\hline
\end{tabular}

Note: Within rows and columns means followed by same letters (lower and upper case, respectively) are not significantly different $(P \geq 0.05)$ by Tukey's HSD test. Fl=Feeding index ( $5^{\text {th }}$ instar larva).

\section{Supplementary Files}

This is a list of supplementary files associated with this preprint. Click to download.

- Supplementarymaterial.docx 